\title{
HELIUM TRANSPORT IN ENHANCED CONFINEMENT REGIMES ON THE TEXTOR \& DIII-D TOKAMAKS
}

by

D.L. HILLIS, J.T. HOGAN, K.H. FINKEN, W.P. WEST, R.R. WEYNANTS, M.R. WADE, K. AKAISHI, W.Y. BAEK, J. BOEDO, K.H. BURRELL, R.W. CONN, K.H. DIPPEL, R. DOERNER, H. EURINGER, D. FINKENTHAL, D.S. GRAY, P. GOHIL, R. GROEBNER, C.C. KLEPPER, A.M. MESSIEN, P.K. MIODUSZEWSKI, A. MIYAHARA, R. MOYER, G. Van OOOST, A. POSPIESZCYK, D. REITER, D. RUSBULDT, R.A. SERAYDARIAN, R. Van NIEUWENHOVE, and G.H. WOLF

APRIL 1992

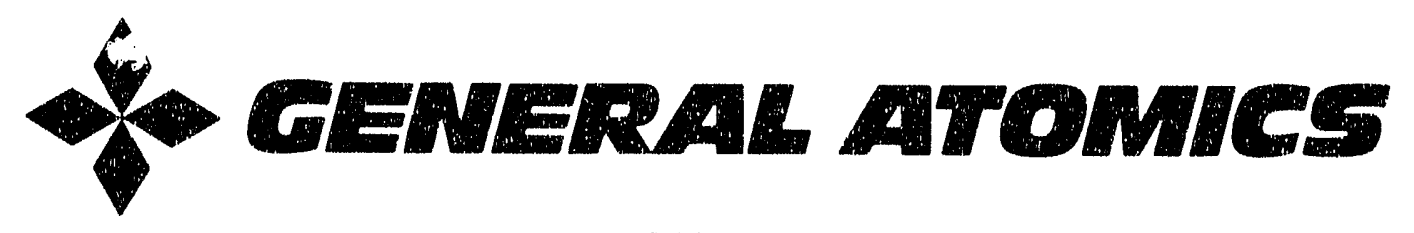

DISTRIBUTION OF THIS DOCUMENT IS UNLIWITED 


\section{DISCLAIMER}

This report was prepared as an account of work sponsored by an agency of the United States Government. Neither th: United States Government nor any agency thereof, nor any of their employees, makes any warrunty, express or implied, or assumes any legal liability or responaibility for the accuracy, completeness, or usefulness of any information, privately prod disclosed, or represents that its use would not infringe privately owned rights. Reference herein to any specific commercial product, process, or service by trade name, trademark, manufacturer, or otherwise, does not necesserily constitute or imply its endorsement, recommendation, or favoring by the United States do not necer any agency thereof. The views and opinions of authorg expreased herein do not necressarily stat \& or reflect those of the United States Government or any agency
thereof. 
GA-A20901

\title{
HELIUM TRANSPORT IN ENHANCED CONFINEMENT REGIMES ON THE TEXTOR \& DIII-D TOKAMAKS
}

\author{
by
}

D.L. HILLIS, * J.T. HOGAN, ${ }^{*}$ K.H. FINKEN, ${ }^{\dagger}$ W.P. WEST, R.R. WEYNANTS, $\ddagger$ M.R. WADE, ${ }^{*}$ K. AKAISHI, $\$$ W.Y. BAEK, J. BOEDO, $\$$ K.H. BURRELL, R.W. CONN, $\$$ K.H. DIPPEL, † R. DOERNER, $\$$ H. EURINGER, †. FINKENTHAL, D.S. GRAY, P. GOHIL, R. GROEBNER, C.C. KL.EPPER, ${ }^{*}$ A.M. MESSIEN ${ }^{\ddagger}$ P.K. MIODUSZEWSKI, A. MIYAHARA, ๆ R. MOYER, $\$$ G. Van OOOST, $\ddagger$ A. POSPIESZCYK, $\dagger$ D. REITER, $\dagger$ D. RUSBULDT, $\dagger$ R.A. SERAYDARIAN, R. Van NIEUWENHOVE, ${ }^{\ddagger}$ and G.H. WOLF ${ }^{\dagger}$

This is a preprint of an invited paper to be presented at the Tenth Plasma Surface Interactions Conference, March 30-April 3, 1992. Monterey, CA, and to be printed in the Proceedings.

Work supported by

Contract No. DE-AC05-840R21400

with Martin Marietta Energy Systems Inc. and Contract No. DE-AC03-89ER51114

for the U.S. Department of Energy

* Oak Ridge National Laboratory.

${ }^{\dagger}$ Association Euratom-KFA, Forschungszentrum Jülich.

$\ddagger$ Associatie "Euratom-Belgische Staat" Ecole Royale Militarie, Brussels.

I National Institute for Fusion Science, Nagoya, Japan.



${ }^{3}$ University of California at L.os Angeles.

University of California at Berke!ey.

GENERAL ATOMICS PROJECT 3466 APRIL. 1992

\section{GENERAL ATOMICS}




\begin{abstract}
Comparisons of helium (He) transport and exhaust in L-mode and in an enhanced confinement regime ( $\mathrm{H}$-mode), which is induced by a polarizing electrode, have been made for the TEXTOR tokamak. The results show an increased tendency for He accumulation when bulk plasma energy and particle confinement are improved during the polarizationinduced $\mathrm{H}$-mode. Since these results imply tha: a high He pumping efficiency may be necessary for $\mathrm{H}$-mode burning plasmas, we have begun exploring $\mathrm{He}$ transport in a divertor $\mathrm{H}$-mode, similar to that proposed for International Thermonuclear Experimental Reactor (ITER). A collaborative program has been initiated to measure He transport and scaling on DIII-D during L-mode. $\mathrm{H}$-mode, and ELMing $\mathrm{H}$-mode plasma conditions. To simulate the presence of He ash in DIII-D, a $25 \mathrm{~ms}$ He puff is injected into a DIII-D plasma resulting in a $\mathrm{He}$ concentration of $\approx 5 \%$. The time dependence of the $\mathrm{He}^{2+}$ density profiles in the plasma core is measured by charge-exchange recombination spectroscopy at 11 radial locations.
\end{abstract}




\section{TABLE OF CONTENTS}

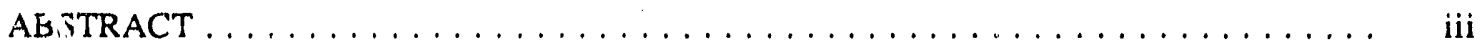

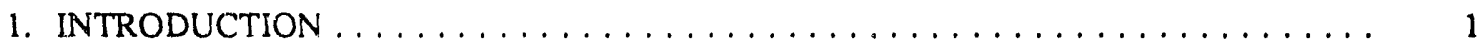

2. THE TEXTOR EXPERIMENTS $\ldots \ldots \ldots \ldots \ldots \ldots \ldots \ldots \ldots \ldots \ldots \ldots \ldots$

3. THE DIII-D EXPERIMENTS $\ldots \ldots \ldots \ldots \ldots \ldots \ldots \ldots \ldots \ldots \ldots \ldots \ldots \ldots$

3.1. DIIl-D He Experiments in L-Mode $\ldots \ldots \ldots \ldots \ldots \ldots \ldots \ldots \ldots \ldots \ldots$

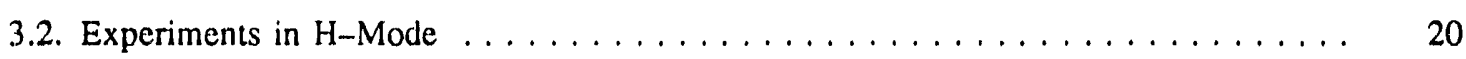

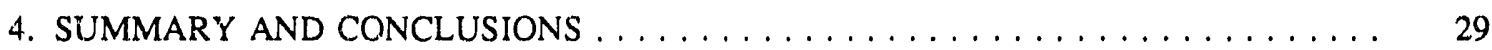

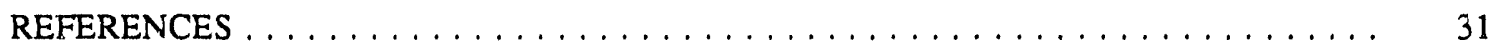

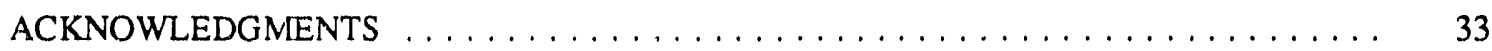




\section{LIST OF FIGURES}

Fig. 1. Poloidal cross section of TEXTOR showing the vacuum ducting from the ALT-II blade to the turbomolecular pumps $\ldots \ldots \ldots \ldots \ldots \ldots \ldots \ldots \ldots \ldots$

Fig. 2. The TEXTOR tokamak with the ALT-Il pumping system $\ldots \ldots \ldots \ldots \ldots \ldots \ldots$

Fig. 3. Line-averaged electron density $\bar{n}_{e}$ and $D_{a}$ intensity as observed from the ALT-II

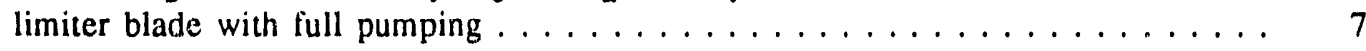

Fig. 4. TEXTOR He density, measured with CER spectroscopy, versus time for two radial

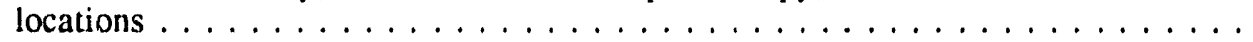

Fig. 5. Electron density and electron temperature profiles, measured via the DIII--D Thomson scattering syßtem, versus the norma ized radius $\rho$ for an L-mode discharge

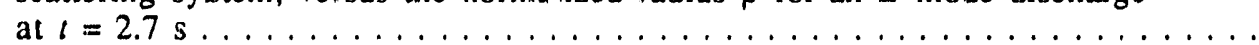

Fig. 6. He density measured with CER spectroscopy versus time on DIII-D for two L-mode

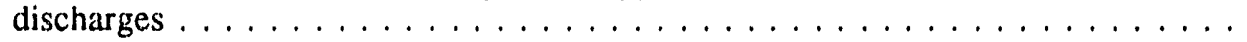

Fig. 7. He density profiles versus time as measured with CER spectroscopy for a high-density

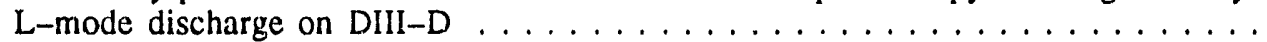

Fig. 8. He density profiles as measured by CER on DIII-D versus the normalized radius $\rho$ at three times during the discharge $\ldots \ldots \ldots \ldots \ldots \ldots \ldots \ldots$

Fig. 9. (a) Electron density and (b) He density profiles versus $r$ as measured by Thomson scattering and CER spectroscopy for an L-mode plasma with

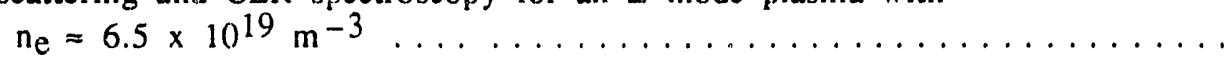

Fig. 10. An H-rnode discharge on DIII-D with an ELM-free period of $500 \mathrm{~ms}$ between $2.0 \mathrm{~s}$ and $2.5 \mathrm{~s}$ followed by a series of giant ELMs, which are separated by

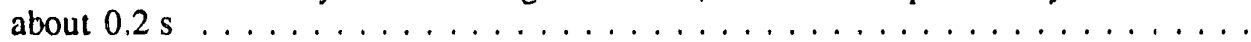

Fig. 11. Helium density evolution versus time for $\mathrm{H}$-mode discharge shown in Fig. $10 \ldots \ldots$

Fig. 12. Typical electron and He density profile for the ELM-free period of discharge 74773

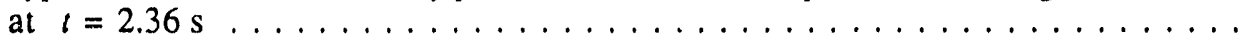

Fig. 13. (a) He density profile, as measured by CER, versus $\rho$ just before and during the giant ELM occurring at $3.0 \mathrm{~s}$ in discharge $74773 \ldots \ldots \ldots \ldots \ldots \ldots \ldots$

Fig. 14. (a) Line-averaged electron density $\bar{n}_{\mathfrak{e}}$ and (b) divertor $D_{a}$ photodiode signal for an $\mathrm{H}$-mode discharge which exhibits high-frequency giant ELMs . . . . . . . .

Fig. 15. The He density as meastied by CER and a spline fit to the electron density measured by Thomson scattering versus $\rho$ for shot 73922 at $t=3.0 \mathrm{~s} \ldots \ldots \ldots \ldots$. 


\section{INTRODUCTION}

For future steady-state tokamaks, such as the International Thermonuclear Experimental Reactor (ITER), continuous purging of the heliurn (He) ash is essential. Estimates [1] show that newly-created He ions must be removed within 7 to 15 energy confinement times to maintain continuous reactor operation $\left(\tau^{*} \mathrm{He} / \tau_{E}<7-15\right)$. Recent measurements [2-6] on TEXTOR and other tokamaks demonstrate that $\mathrm{He}$ can be readily transported from the plasma core during $\mathrm{L}-$ mode plasma discharges. TEXTOR experiments use the Advanced Limiter Test-II (ALT-II) system, a toroidal belt pump limiter [5] with turbomolecular pumps (TMPs) that can completely remove the He from the system. In other tokamak experiments, He transport with no He removal has been investigated; in others, He removal from the plasma due to wall pumping has been observed.

The next generation of tokamaks, such as ITER, are designed to operate in the enhanced confinement or $\mathrm{H}$-mode regime, where the core plasma He particle confinement time is expected to be better than that for L-mode [7]. The ITER ignition requirements assume that helium density in the core can be regulated by low-level edge-localized mode (ELM) and sawtooth activity, without undue adverse effects on energy confinement. However, if He confinement in the core is too good in $\mathrm{H}$-mode, very efficient particle removal schemes must be devised to remove the $\mathrm{He}$ ash.

In an earlier series of measurements on TEXTOR $[2,3]$, which investigated He transport for $\mathrm{L}$-mode discharges, it was demonstrated that $\tau^{*} \mathrm{He} / \tau_{E} \approx 9-20$; this range of values for $\tau^{*} \mathrm{He} / \tau_{E}$ appears to be adequate for reactor ash control. The value of $\tau^{*} \mathrm{He} / \tau_{E}$ is a simplified figure of merit for a reactor, where $\tau^{*} \mathrm{He}=\tau_{\mathrm{He}} /(1-R), R$ is the global recycling coefficient, $\tau_{\mathrm{He}}$ is the helium particle confinement time, and $\tau_{E}$ is the energy confinement time. In recent experiments on TEXTOR with ALT-II pumping, an enhanced confinement regime (or H-mode-like) plasma is produced by an edge polarization electrode [8-10]. The transport and exhaust of He during 
this enhanced confinement regime are compared with those observed in L-mode discharges. For the DIII-D experiment, which is currently without active He pumping, we investigate the influence of ELMs on He spatial profiles and compare these profiles with "ELM free" or L-mode He spatial profiles.

On both tokamaks, we simulate the presence of recycled He ash in a tokamak plasma by puffing $\mathrm{He}\left(\approx 5 \%\right.$ relative to $\left.\bar{n}_{\mathrm{e}}\right)$ into the plasma during neutral beam injection $(\mathrm{NBI})$. The transport of He into the plasma core and its subsequent pumpout (in the case of TEXTOR/ ALT-II) are observed using charge-exchange recombination (CER) spectroscopy [11], in combination with NBI. Measuring spatially and temporally resolved ion temperatures and absolute densities using CER line intensities is a well-established technique on many tokamaks [11-14]. The CER spectroscopy is used to obtain the local $\mathrm{He}^{2+}$ density in the plasma core at various locations along the minor radius by observing the $\mathrm{He}^{+}(4 \rightarrow 3)$ transition at $4686 \AA$ with absolutely calibrated spectrometers that view the neutral beam. Detailed line shape analysis and modeling of neutral beam penetration allow the $\mathrm{He}^{2+}$ density to be determined to $\pm 30 \%$. The TEXTOR experiments will be described in Section 2 and the DIII--D experiments in Section 3. The summary and conclusions will be presented in Section 4. 


\section{THE TEXTOR EXPERIMENTS}

The TEXTOR plasma [15] for these experiments has a major radius $R=175 \mathrm{~cm}$, a plasma current $I_{\mathrm{p}}=190 \mathrm{kA}$, a toroidal magnetic field of $2.25 \mathrm{~T}$, and boronized walls. To provide active CER measurements, a $160 \mathrm{~kW} \mathrm{H} \mathrm{H}^{\circ}$ beam was injected between $0.6 \mathrm{~s}$ and $2.3 \mathrm{~s}$ after discharge initiation, with a short $(10 \mathrm{~ms})$ He puff injected at $t=1.0 \mathrm{~s}$, causing a rise in the average electron density $\bar{n}_{\mathrm{e}}$. Typically, the central electron temperature $T_{\mathrm{e}} \approx 1.0 \mathrm{keV}$.

The ALT-II limiter [15] is the primary limiter and was positioned at a minor radius $r=$ $46 \mathrm{~cm}$. It consists of eight graphite blade segments that form an axisymmetric toroidal belt. Each blade is equipped with a particle collection scoop, which is connected via vacuum ducting to a turbo-molecular pump (TMP) and is shown in Fig. 1. The total effective pumping speed at the neutralizer plate for all eight limiter blades is $S_{\text {eff }}=5200 \mathrm{~L} / \mathrm{s}$. A maximum He exhaust efficiency of $\sim 8 \%$ is estimated [3]. The total He exhaust efficiency is $\varepsilon=\mathrm{p}_{\mathrm{O}} \mathrm{S}_{\mathrm{eff}} / \mathrm{\Gamma}_{\mathrm{O}}$, where $\mathrm{p}_{\mathrm{o}}$ is the He pressure measured in the pumping duct, $\mathrm{p}_{\mathrm{o}} \mathrm{S}_{\text {eff }}$ is the He removal rate, and $\Gamma_{\mathrm{o}}$ is the He plasma efflux measured with a calibrated He monitor that views the ALT-II limiter.

In the plasma edge, the He particle flux at the ALT-II limiter is measured with an absolutely calibrated photodiode and interference filter $(4686 \AA)$ combination that views a poloidal section of the limiter blade at one toroidal location. The He recycling is assumed to be toroidally symmetric, and the total He recycling flux at the ALT-II blade is estimated by multiplying the measured flux by the appropriate geometric factor. The neutral $\mathrm{He}$ and $\mathrm{D}_{2}$ partial pressures in the ALT-II pumping duct are measured from the $\mathrm{He}(5875 \AA)$ and $\mathrm{D}_{\alpha}(6563 \AA)$ light emerging from a modified Penning gas discharge (see Refs. $[16,17])$.

Earlier papers [8-10] have described how an improved confinement (or $\mathrm{H}$-mode-like) regime has been achieved in TEXTOR by using a polarization electrode to induce strong radial electric fields and poloidal rotation velocities in the plasma edge of ohmic and auxiliary-heated plasmas. 


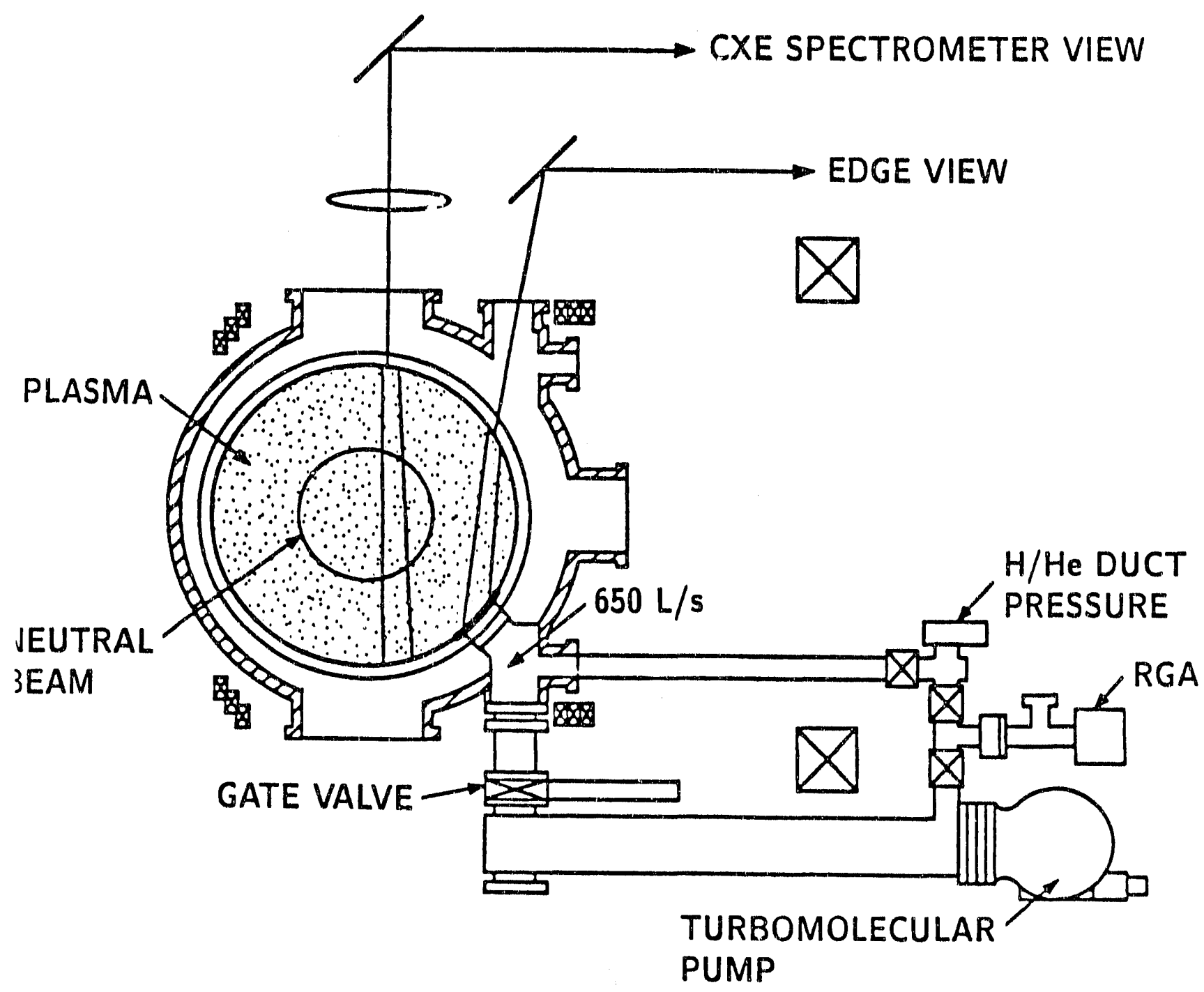

Fig. 1. Poloidal cross section of TEXTOR showing the vacuum ducting from the ALT-il blade to the turbomolecular pumps. The penning gauge measures the He partial pressure in the pumping ducts. 
The details of the polarization electrode are described in Ref. [10] and a bias voltage of $+900 \mathrm{~V}$ (i.e. radially outward electric field) is applied between the electrode and the ALT-II belt limiter for these measurements. To produce the enhanced confinement plasmas, the insulating shaft of the biasing electrode is introduced $6 \mathrm{~cm}$ beyond the toroidal belt limiter $(r=46 \mathrm{~cm})$, as shown in Fig. 2. Comparison of fluxes from the electrode and from the ALT-II blades shows that the polarization electrode does not itself become the main limiter. Using the polarization electrode, clear $\mathrm{H}$-mode signatures (e.g., density rise, reduced $\mathrm{D}_{\alpha}$ emission, profile steepening) occur, and improvements of about 1.4 in the energy and 2 to 2.5 in the particle confinement time [10] are deduced.

The temporal evolution of $\bar{n}_{\mathrm{e}}$ and of the $\mathrm{D}_{\alpha}$ signal are shown in Fig. 3(a-c) for three discharges with full ALT-II pumping and with neutral beam injection. Figure 3(a) shows $\bar{n}_{\mathrm{e}}$ and the $\mathrm{D}_{\alpha}$ signal for the case without bias on the polarization electrode, while Figs. 3(b) and 3(c) are with $+900 \mathrm{~V}$ bias on the polarization electrode. The neutral beam power injected for Fig. 3(b) is $90 \mathrm{~kW}$ while the neutral beam power is $160 \mathrm{~kW}$ in Fig. 3(c). In these discharges a short puff of $\mathrm{He}(10 \mathrm{~ms})$ is injected from the wall into the plasma at $0.6 \mathrm{~s}$. The polarization voltage is ramped up from $0.7 \mathrm{~s}$ to $1 \mathrm{~s}$, held constant for $0.8 \mathrm{~s}$ at $+900 \mathrm{~V}$ and then ramped down. The neutral beam is injected for $\mathrm{He}^{2+}$ density measurements via CER from 1.3 to $1.8 \mathrm{~s}$. In Fig. 4 , the $\mathrm{He}^{2+}$ density versus time is shown at two radial locations within the plasma core $(r=-4$ and $25 \mathrm{~cm})$ during full pumping with ALT-II and with and without $+900 \mathrm{~V}$ bias applied to the polarization electrode. The discharge shown in Fig. 4 is similar to the discharge 45536 shown in Fig. 3(b) without the presence of ELMs, but the NBI power and polarization bias remain on for a longer measurement time, so that the exhaust time of the $\mathrm{He}\left(\tau^{*} \mathrm{He}\right)$ can be observed over a longer period of time. For the discharges in Fig. 4, the neutral beam is injected between $0.6 \mathrm{~s}$ and $3.0 \mathrm{~s}$, while the polarization bias is applied between $0.8 \mathrm{~s}$ and $2.8 \mathrm{~s}$ with a $10 \mathrm{~ms}$ puff of $\mathrm{He}$ injected at $1.0 \mathrm{~s}$. In Figs. 3 and 4 the He density rises sharply just after the He gas puff, and the He appears in the plasma core within $100-200 \mathrm{~ms}$. The $\mathrm{He}^{2+}$ density in the plasma core agrees well with the observed rise in $\bar{n}_{\mathrm{e}}$. 


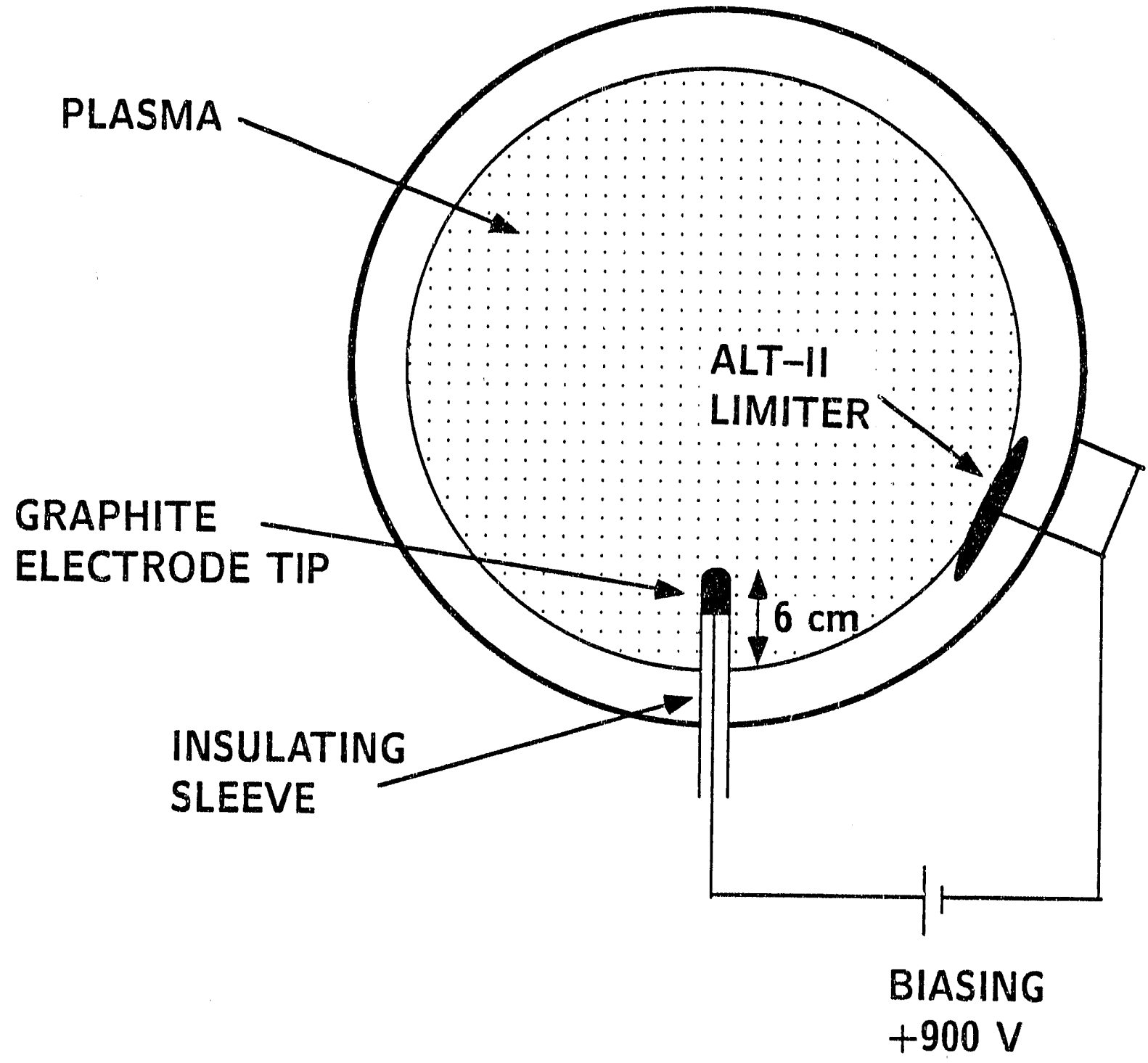

Fig. 2. The TEXTOR tokamak with the ALT-II pumping system. The polarization electrode biasing system is shown. For these measurements the bias voltage was $+900 \mathrm{~V}$. 


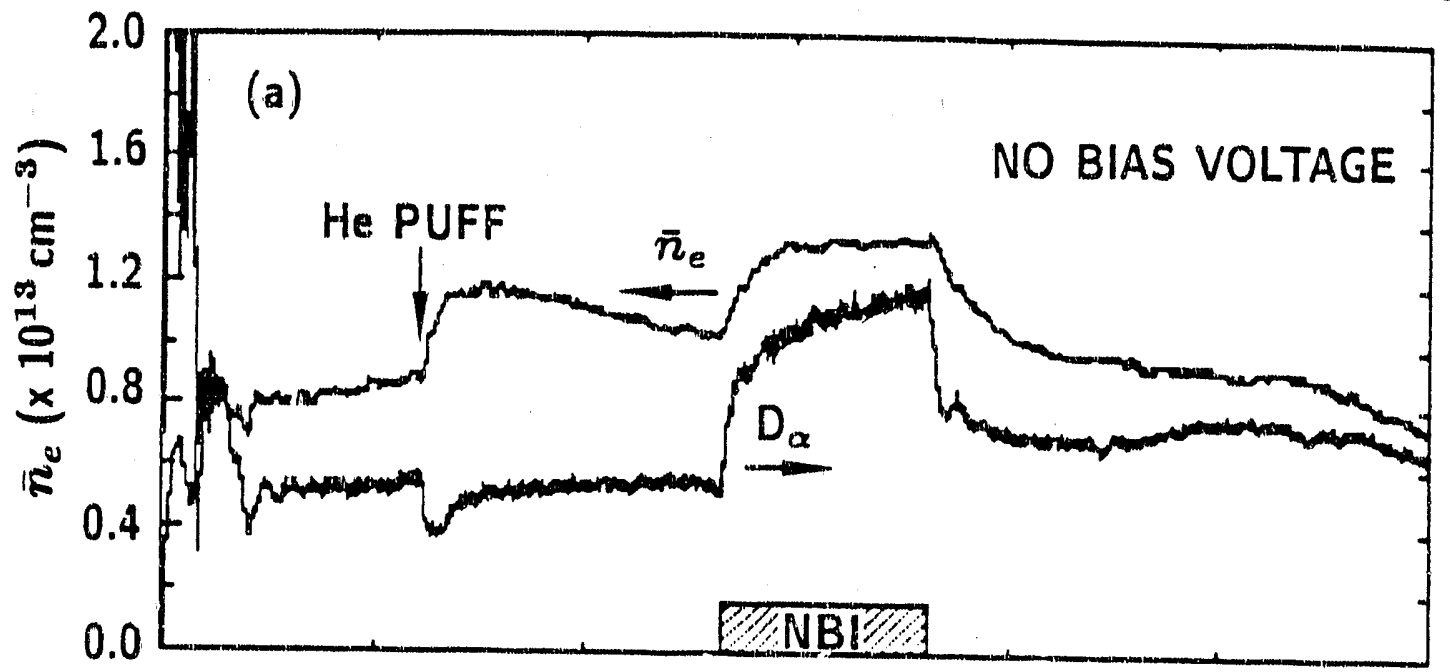

5.0

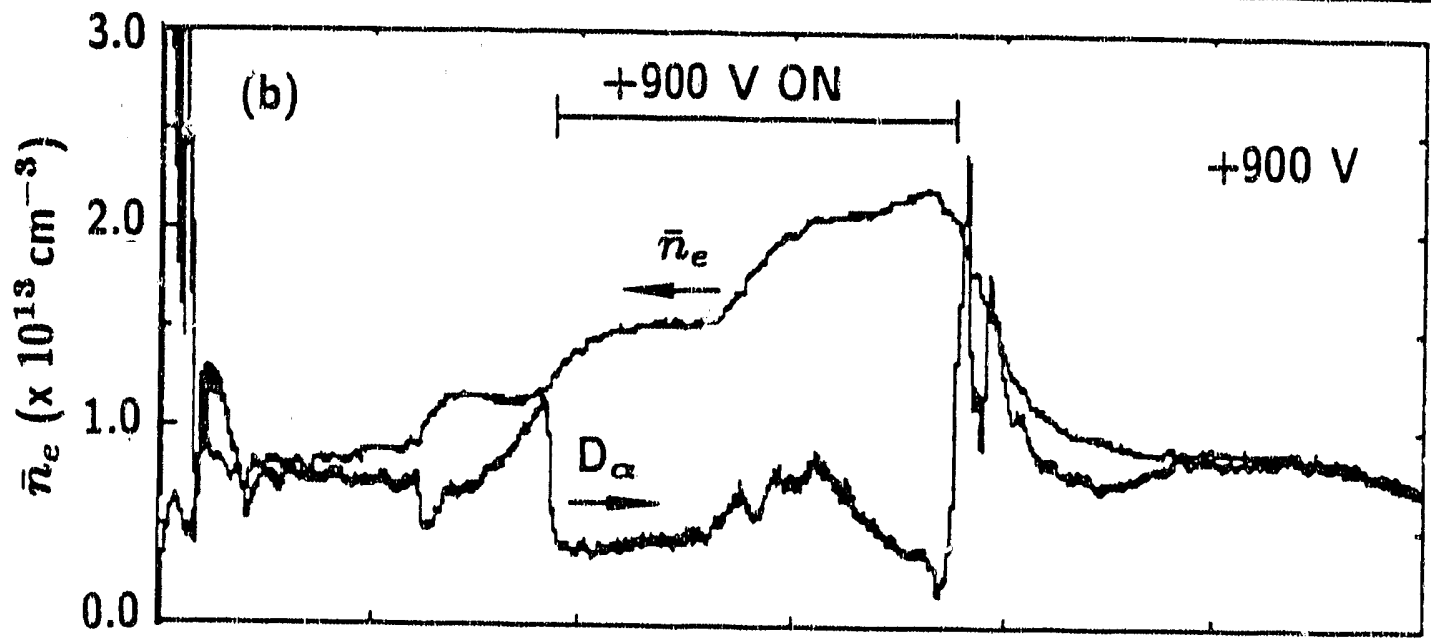

5.0

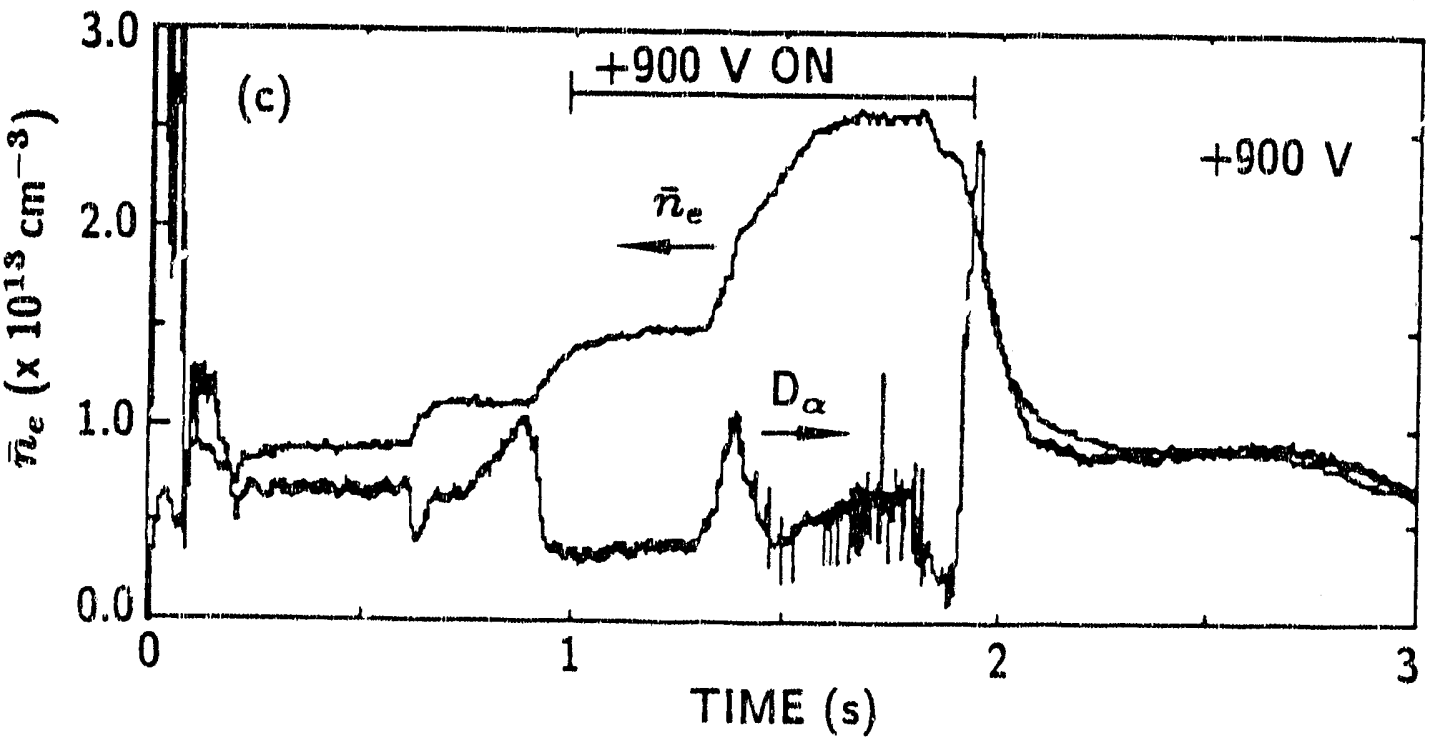

Fig. 3. Line-averaged electron density $\bar{n}_{\mathrm{e}}$ and $\mathrm{D}_{\mathrm{a}}$ intensity as observed from the ALT-11 limiter blade with full pumping. (a) No polarization voltage, $160 \mathrm{~kW}$ of NBI power. (b) Polarization voltage of $+900 \mathrm{~V}$ on polarization electrode (see Fig. 1) and $90 \mathrm{~kW}$ of NBI power. (c) Polarization voltage of $+900 \mathrm{~V}$ on the polarization electrode (see Fig. 1) and $160 \mathrm{~kW}$ of NBI power. A $10 \mathrm{~ms}$ He puff is injected at $t=0.6 \mathrm{~s}$. 


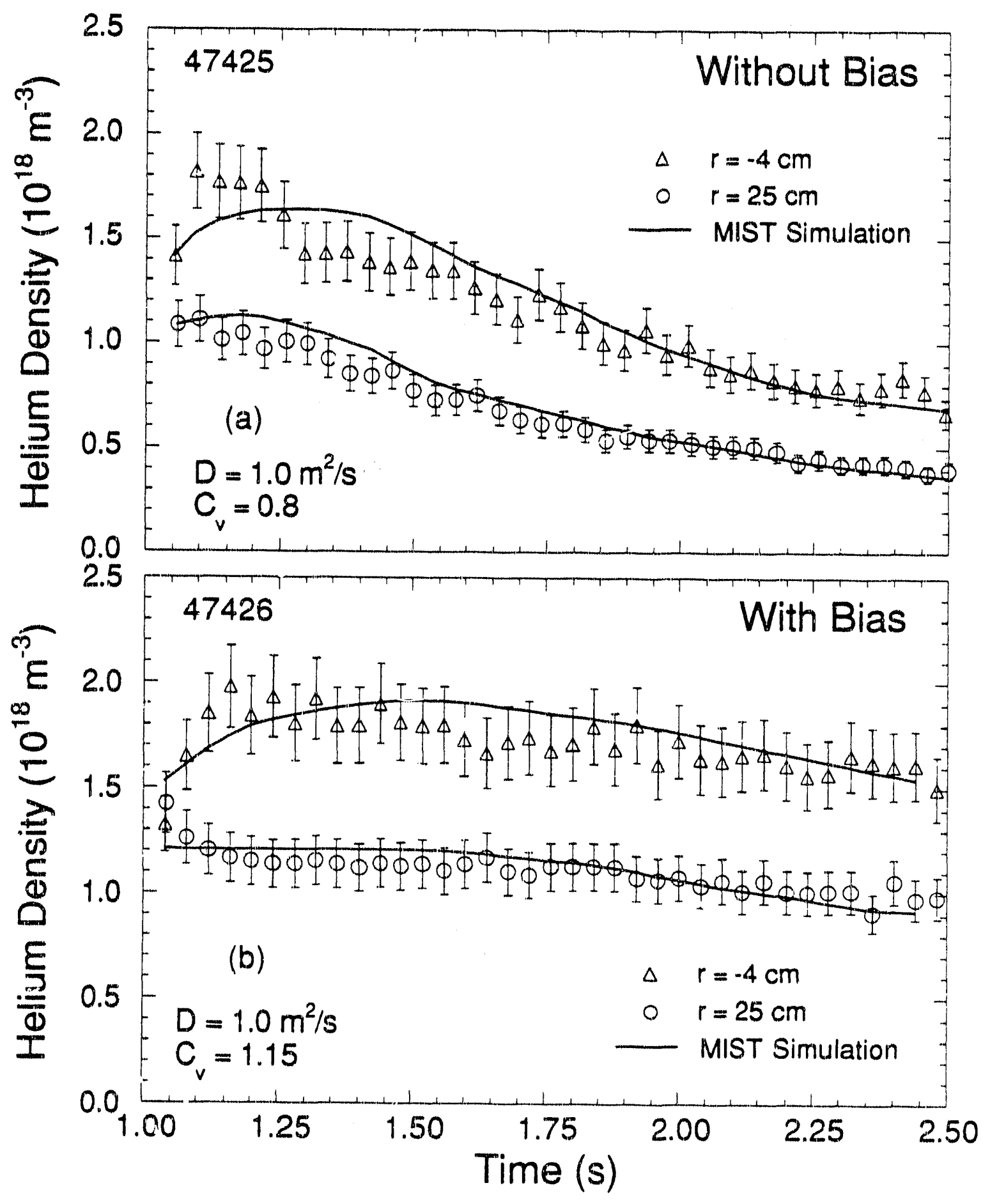

Fig. 4. TEXTOR He density, measured with CER spectroscopy, versus time for two radial locations $(r=-4$ and $25 \mathrm{~cm}$ ) (a) for shot 47425 after a short He puff at $0.6 \mathrm{~s}$ with full ALT-II pumping, $60 \mathrm{~kW} \mathrm{NBI}$, and no bias applied to the polarization electrode and (b) for shot 47426, with the sarne conditions except that a $+900 \mathrm{~V}$ bias is applied to the polarization electrode. Points: $\mathrm{He}^{2+}$ density data. Solid lines: MIST transport calculations with $R_{\mathrm{He}}=0.92, D_{A}=1.0 \mathrm{~m}^{2} / \mathrm{s}, C_{V}=0.8$ for 47425 and $C_{V}=1.15$ for 47426 . 
For the case without pumping (not shown), the $\mathrm{He}^{2+}$ density remains constant after the initial rise, indicating full recycling of the $\mathrm{He}$ (recycling coefficient $R_{\mathrm{He}} \approx 1.0$ ), as reported in Ref. [2]. For the L-mode discharges with full ALT-II pumping reported in Ref. [2], the $\mathrm{He}^{2+}$ density drops rapidly and $\sim 90 \%$ of the He puffea into the discharge is exhausted within $\approx 1.0 \mathrm{~s}$. A typical low density $\left(\bar{n}_{\mathrm{e}}=1 \times 10^{13} \mathrm{~cm}^{-3}\right)$ L-mode discharge similar to those reported in Ref. [2] with full ALT-II pumping is shown in Figs. 3(a) and 4(a), In Fig. 3(a), the characteristic behavior of $L$-mode discharges is seen: as neutral beam power is added between $1.3 \mathrm{~s}$ and $1.8 \mathrm{~s}, \bar{n}_{\mathrm{e}}$ and the $\mathrm{D}_{\alpha}$ signal increase. The He partial pressure (not shown) within the pumping duct increases and the $\mathrm{He}^{2+}$ density drops rapidly after the initial gas puff [Fig. 4(a)]. The exhaust efficiency for these $\mathrm{L}$-mode discharges is found to be $8 \%$ to $10 \%$, as in our earlier measurements [2].

When $+900 \mathrm{~V}$ is applied to the polarization electrode $(t \approx 1.0-1.8 \mathrm{~s})[8-10]$, a clear transition to an enhan ed confinement regime is achieved [Figs. 3(b) and 3(c)]. This regime (or $\mathrm{H}$-mode-like behavior) is evidenced by a strong increase in $\bar{n}_{\mathrm{e}}$ and a sharp decrease in the $\mathrm{D}_{\alpha}$ signal, both of which indicate an increase in the deuterium particle confinement time. The $D_{\alpha}$ signal during this enhanced confinement condition is relatively quiet in Fig. 3(b) for $90 \mathrm{~kW}$ of NBI power, whereas Fig. 3(c) shows evidence of large fluctuations (ELM-like behavior) with $160 \mathrm{~kW}$ of NBI. In Fig. 3(b) where the $\mathrm{D}_{\alpha}$ signal does not exhibit large fluctuations, the He partial pressure in the pumping duct is reduced by about a factor of 4 during the enhanced confinement condition compared to typical L-mode values.. Alternatively, if ELM-like fluctuations are present in the $D_{\alpha}$ signal, the He partial pressure is only reduced by about a factor of 2. More details of these polarization measurements and pressure measurements can be found in a forthcoming publication [18].

In Fig. 4 the $\mathrm{He}^{2+}$ density measured in the plasma core by CER is shown for an enhanced confinement condition similar to that of $\mathrm{Fi}_{6}$. 3(b), where ELMs were not present. Clearly, the $\mathrm{He}^{2+}$ density in Fig. 4 remains almost $u$ thanged throughout the plasma discharge during both NBI and the biasing phase of the polarization electrode, even though full ALT-II pumping is 
applied. This is, of course, consistent with the observation that little He is being conducted into the pumping duct. The data of Fig. 4 can be used to determine the He particle confinement time, $\tau^{*} \mathrm{He}$, from the decay of the He density. For the discharges shown in Fig. 4 , the beam power was quite low $(60 \mathrm{~kW})$ and was serving primarily as a diagnostic neutral beam for the CER measurements. For the L-mode case of Fig. 4(a) there was no electrode biasing and $\tau^{*} \mathrm{He} \approx$ $1.2 \mathrm{~s}$. In the $\mathrm{H}$-mode case of Fig. 4(b) the polarization bias was used to induce the enhanced confinement $\mathrm{H}$-mode, and $\tau^{*} \mathrm{He} \approx 3.2 \mathrm{~s}$. The energy confinement time for these discharges is $\tau_{\mathrm{E}} \approx 0.045 \mathrm{~s}$.

The data in Fig. 4 have been modeled with the multil le impurity species transport (MIST) impurity transport code [19]. MIST uses as input the experimentally measured $n_{\mathrm{e}}$ (HCN interferometer) and $T_{\mathrm{e}}$ (electron cyclotron emission) profiles as functions of radius and time. The code computes the $\mathrm{He}^{2+}$ density profiles as a function of time and compares them with the measured $\mathrm{He}^{2+}$ density measurements at $r=-4 \mathrm{~cm}$ and $r=25 \mathrm{~cm}$. The code requires as input a spatially dependent anomalnus diffusivity, $D_{\mathrm{A}}$, a pinch velocity $\left[n_{\mathrm{e}} \mathrm{v}(r)=C_{\mathrm{v}} D_{\mathrm{A}}\left(d n_{\mathrm{e}} / d r\right)\right.$, where $\mathrm{v}_{\mathrm{p}}$ is parameterized by the pinch coefficient, $C_{\mathrm{v}}$ ], and a global recycling coefficient $R_{\mathrm{He}}$, which is 0.92 for these full pumping cases [2]. The MIST results are shown in Fig. 4 as solid lines for comparison with the $\mathrm{He}^{2+}$ data points. The transport coefficients needed to match the He evolution, $D_{A} \approx 1.0 \mathrm{~m}^{2} / \mathrm{s}$ and $C_{\mathrm{v}} \approx 0.8$ for the L-mode discharge [Fig. 4(a)] are similar to those found in earlier transport experiments [3]. For the polarization induced $\mathrm{H}$-mode, a diffusivity of $D_{A} \approx 1.0 \mathrm{~m}^{2} / \mathrm{s}$ is again found to match the profiles, while $C_{\mathrm{V}}$ must be increased to 1.15 , if $R_{\mathrm{He}}=0.92$ as was found for the earlier L-mode measurements. (Note that the L-mode case of Ref. [3] had strong sawtoothing activity, with $r_{\mathrm{s}} / \mathrm{a}=0.15$.)

In summary, these He transport experiments, in conjunction with the ALT-II purnping system, have provided a first estimate of fundamental He transport processes under conditions where both recycling and the type of confinement ( $\mathrm{L}$-mode versus $\mathrm{H}$-mode) is controlled and varied. The experimental data have shown that He exhaust and transport mechanisms may be significantly different in the two confinement modes. When He is puffed into the L-mode-type 
discharges, it quickly appears in the plasma core and is radially transported to the plasma boundary, where it is readily removed within about $1 \mathrm{~s}$ by the ALT-II pump limiter. For the enhanced confinement plasmas the $\mathrm{He}^{2+}$ is maintained within the plasma core for very long periods of time (2-3 times $\tau^{*}{ }_{\mathrm{He}}$ in L-mode) and is not readily transported to the pumping duct for removal; for these plasmas, the He pressures in the pumping duct were found to decrease by a factor of 2-4 over similar L-mode conditions. However, with the appearance of large ELM-like fluctuations the He pressure in the duct did increase. Transport modeling has shown that, the diffusivity is kept fixed, the inward pinch coefficient $C_{\mathrm{v}}$, which characterizes the peaking of the He density profile relative to the $n_{\mathrm{e}}$ profile, increases under enhanced confinement conditions. More detailed knowledge of the He radial profile as a function of time during the He influx and pump-out phase is needed to determine $C_{\mathrm{V}}$ and $D_{\mathrm{A}}$ uniquely. From these data for the ALT-II configuration, the polarization-induced enhanced confinement regime increases $\tau^{*} \mathrm{He} / \tau_{E}$ to about 70 , as compared to the $\mathrm{L}-$ mode value of $9-20$. These measurements suggest that He removal may be more difficult in the enhanced confinement (or $\mathrm{H}$-mode-like) plasmas of future burning plasmas, such as ITER, than was found initially [2-6] for L-mode type plasmas. However, neither the control of the particle confinement via ELMs nor the control of the sawtooth frequency was tested in these experiments. The CER spectroscopy system on TEXTOR is currently being upgraded to provide up to 15-point radial He profiles. The effects of ELMs on He spatial profiles are discussed in Section 3. 


\section{THE DIII-D EXPERIMENTS}

On DIII-D, $\mathrm{He}^{2+}$ profiles are measured with the CER spectroscopy system previously developed for ion temperature and rotational velocity' measurements $[13,20]$. As presently configured, the system consists of four spectrometers, each with eight viewing chords. A total of 31 chords are arranged to view across two neutral beam lines, with 16 chords viewing the beams tangentially through the plasma and 15 viewing vertically (one vertical chord views the plasma outside the beam envelope). Each chord is arranged such that within the viewing volume constituted by the intersection of the chord and the neutral beam, the view is nearly tangent to the local flux surface and thus excellent radial resolution is achieved $(\approx \pm 1 \mathrm{~cm}$ in the worst case). Both tangential and vertical views extend from the typical plasma magnetic axis $(R=1.67 \mathrm{~m})$ to beyond the typical separatrix $(R=2.28 \mathrm{~m})$. For the He transport work presented here, an integration time of $10 \mathrm{~ms}$ is typically chosen,. Absolute calibration of the sensitivity of each chord has been taccomplished using standard calibration lamps, supplemented with two techniques involving (1) injection of the neutral beam into a gas-filled torus and (2) NBI into a pure He plasma. The absolute calibration of each CER chord and modeling of the attenuation of the DIII-D neutral beams is described in a forthcoming pubiication [20].

\subsection{DIII-D He Experiments in L-Mode}

The DIII-D plasma for these experiments had a major radius $R=1.76 \mathrm{~m}$, a plasma current $I_{\mathrm{p}}=1.6 \mathrm{MA}$, a toroidal magnetic field of $2.1 \mathrm{~T}$, and boronized walls. The magnetic configuration was a double-null divertor discharge. The $\mathrm{D}^{\circ}$ beams were injected between $1.8 \mathrm{~s}$ and $3.8 \mathrm{~s}$ after discharge initiation, with a short $(25 \mathrm{~ms})$ He puff injected at $t=2.3 \mathrm{~s}$, causing a rise

in the average electron density $\bar{n}_{\mathrm{e}}$. Electron temperature and electron density spatial profiles for 
the low density L-mode shot (74759) are shown in Fig. 5 at $t=2.7 \mathrm{~s}$ as a function of the normalized radius, $\rho$. The value $\rho=0$ indicates the magnetic axis of the discharge, and $\rho=1.0$ indicates the separatrix. To investigate He transport on DIII-D in L-mode discharges so that the results could be compared with those from TEXTOR, a $25 \mathrm{~ms}$ puff of He was injected from the divertor floor into the vacuum vessel of DIII-D during two L-mode discharges ( 74759 with $\mathrm{n}_{\mathrm{e}} \approx$ $3.5 \times 10^{19} \mathrm{~m}^{-3}$ and 74761 with $n_{\mathrm{e}} \approx 6.5 \times 10^{19} \mathrm{~m}^{-3}$ ). Figures $6(\mathrm{a})$ and $6(\mathrm{~b})$ show the time evolution of the He density in the plasma core as a function of time after the gas puff at $t=2.3 \mathrm{~s}$ for the two L-mode discharges. In both cases the He rises quickly after the gas puff and takes typically about $150 \mathrm{~ms}$ to reach the innermost CER chord located at $\rho=0.32$. Since there is presently no pumping on DIII-D, the He recycling coefficient must be close to unity, and the $\mathrm{He}$ density is found to reach a constant value about $200 \mathrm{~ms}$ after the He gas puff. To indicate the wealth of information obtained by CER, a three-dimensional plot of the He spatial profile versus time is shown for Shot 74761 in Fig. 7, while Fig. 8 contains individual tirne slices of the He spatial profile from Shot 74759 at times just before $(t=2.28 \mathrm{~s})$, just after $(t=2.36 \mathrm{~s})$, and well after $(2.70 \mathrm{~s})$ the He gas puff at $2.3 \mathrm{~s}$. The solid lines of Fig. 8 are spline fits to the Thomson scattering measurements of the electron density profile, which have been normalized to the CER He density measurements at $\rho=0.23$, such that the shape of the He density and electron density profile can be compared. Clearly, the electron density and He density profiles have similar shapes for the "steady state" profiles at $2.28 \mathrm{~s}$ and $2.70 \mathrm{~s}$. Some departure of the He density data is noted during the period just after the gas puff at $t=2.36 \mathrm{~s}$, however, this difference may be influenced by the fact that the Thomson measurement is an instantaneous measurement, while the CER measurement is integrated over $10 \mathrm{~ms}$.

In Fig. 9, a time slice $(t=2.44 \mathrm{~s})$ of the He density profile for shot 74761 (shown in Fig. 7) is also sh swn for comparison with the corresponding Thomson scattering electron density profile. Once again, the shapes are consistent. The solid line superimposed on the He density data of Fig. 9 is a MIST calculation for this high density L-mode discharge. For this high density $\mathrm{L}$-mode case, $D_{A} \approx 1.0 \mathrm{~m}^{2} / \mathrm{s}$ and $C_{\mathrm{V}} \approx 0.9$. These values are quite similar to 


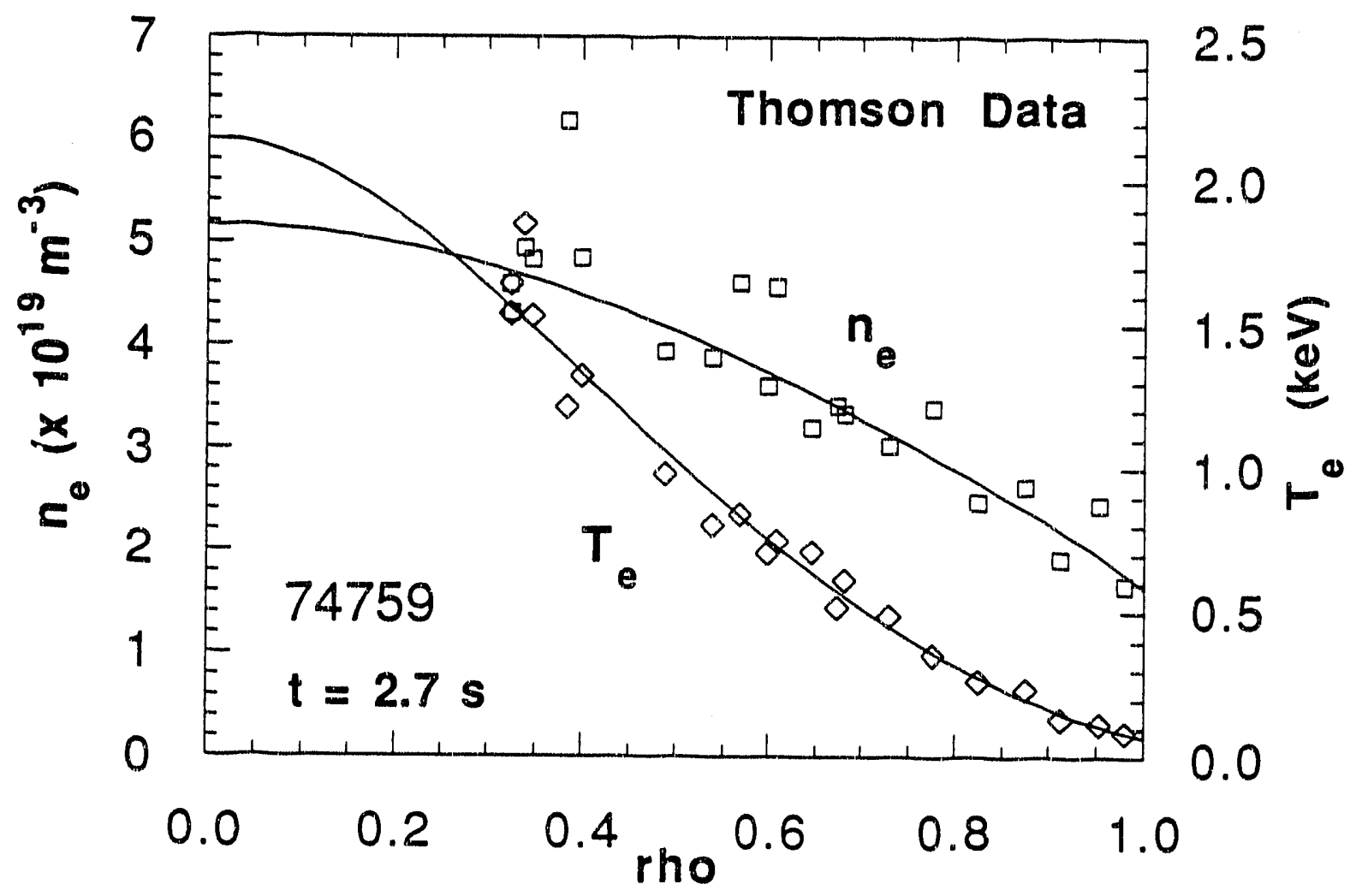

Fig. 5. Electron density and electron temperature profiles, measured via the DIII-D Thomson scattering system, versus the normalized radius $\rho$ for an $L-$ mode discharge at $t=2.7 \mathrm{~s}$. 

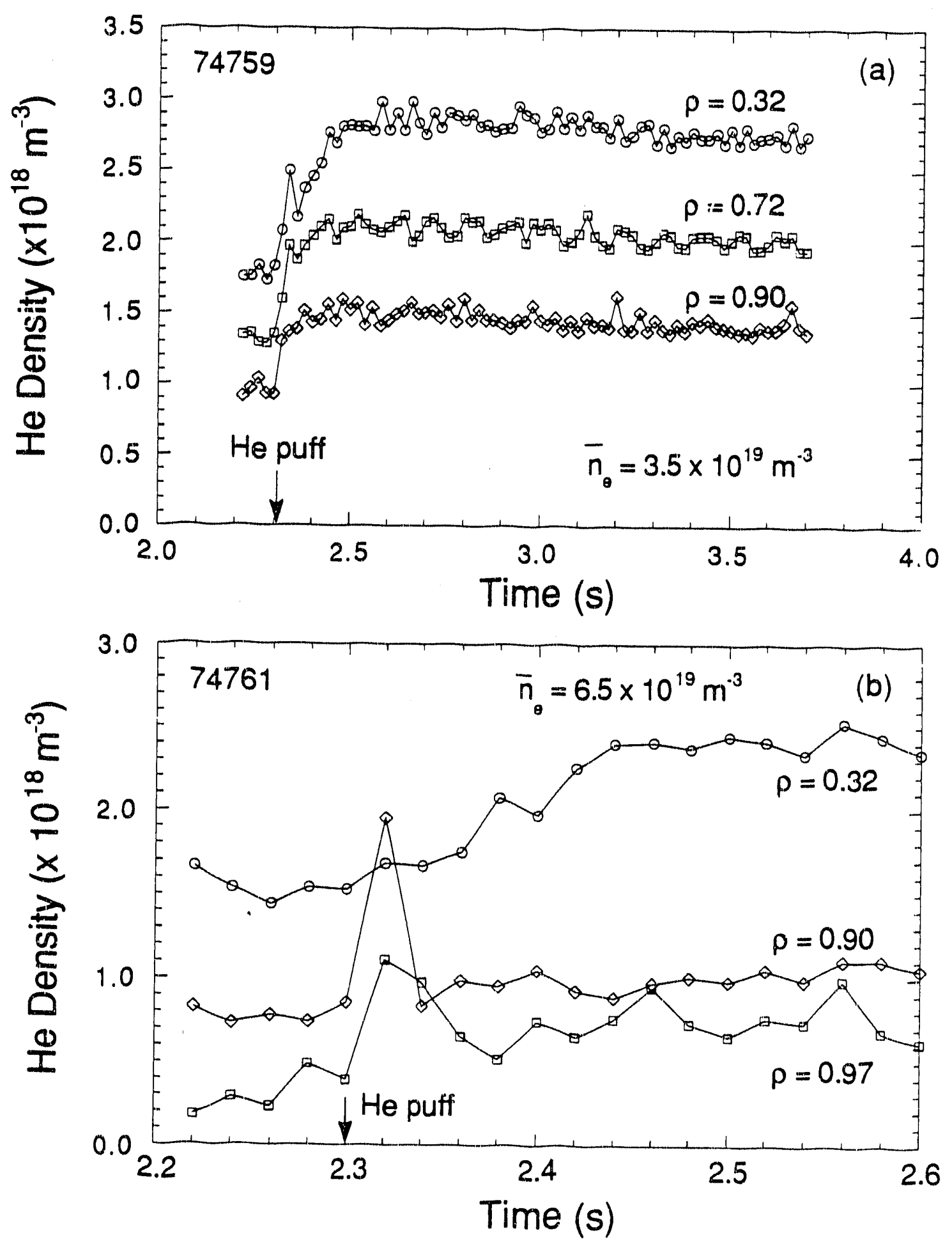

Fig. 6. He density measured with CER spectroscopy versus time on DIII-D for two L-mode discharges: (a) for a low-density discharge with $\bar{n}_{\mathrm{e}} \approx 3.5 \times 10^{19} \mathrm{~m}^{-3}$, and (b) a high-density discharge, $\bar{n}_{\mathrm{e}} \approx 6.5 \times 10^{19} \mathrm{~m}^{-3}$. For each discharge a $25 \mathrm{~ms}$ He puff is injected at $t=2.3 \mathrm{~s}$. Curves are labeled with the value of the normalized radius $\rho$ that corresponds to that particular viewing chord. 


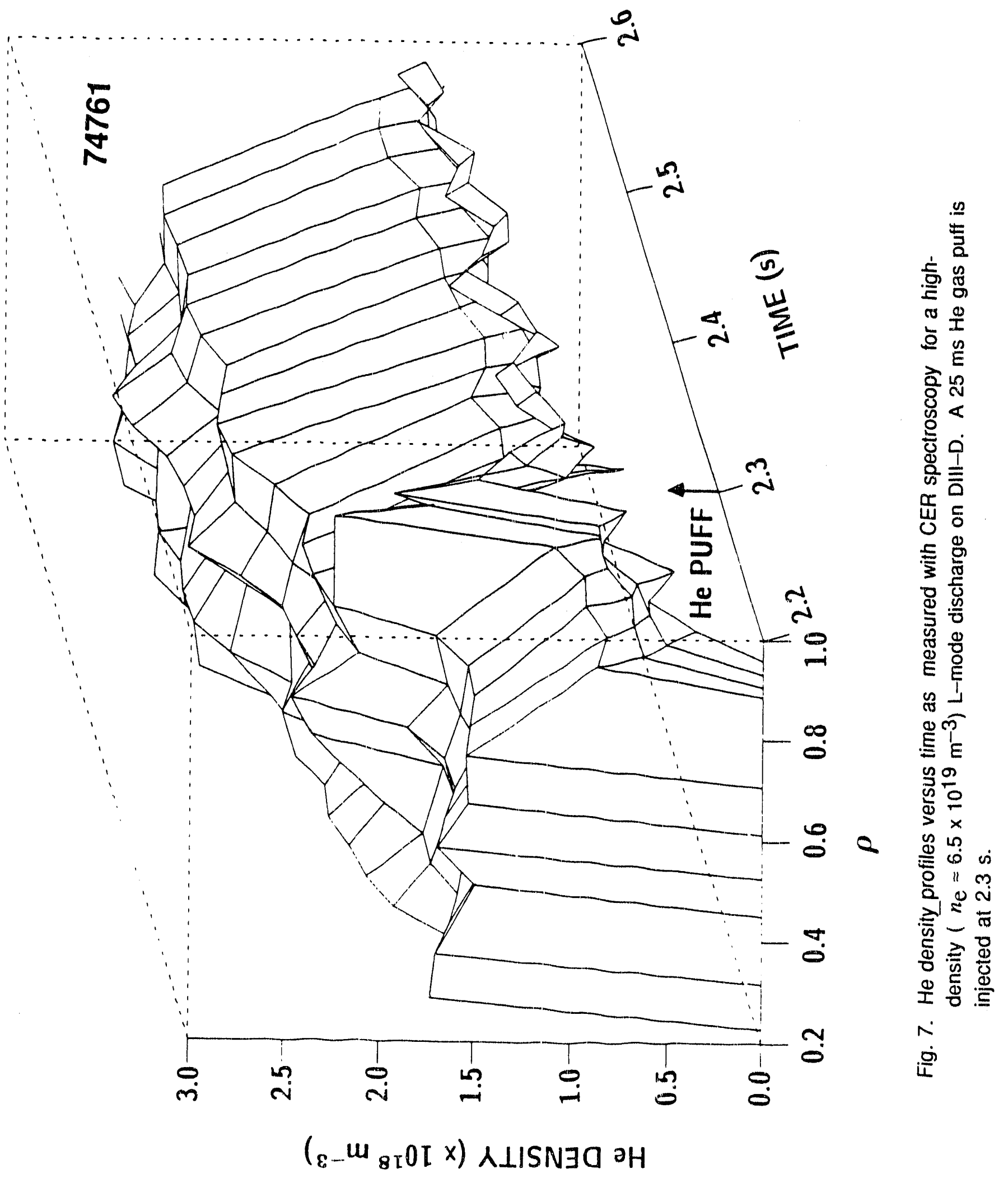




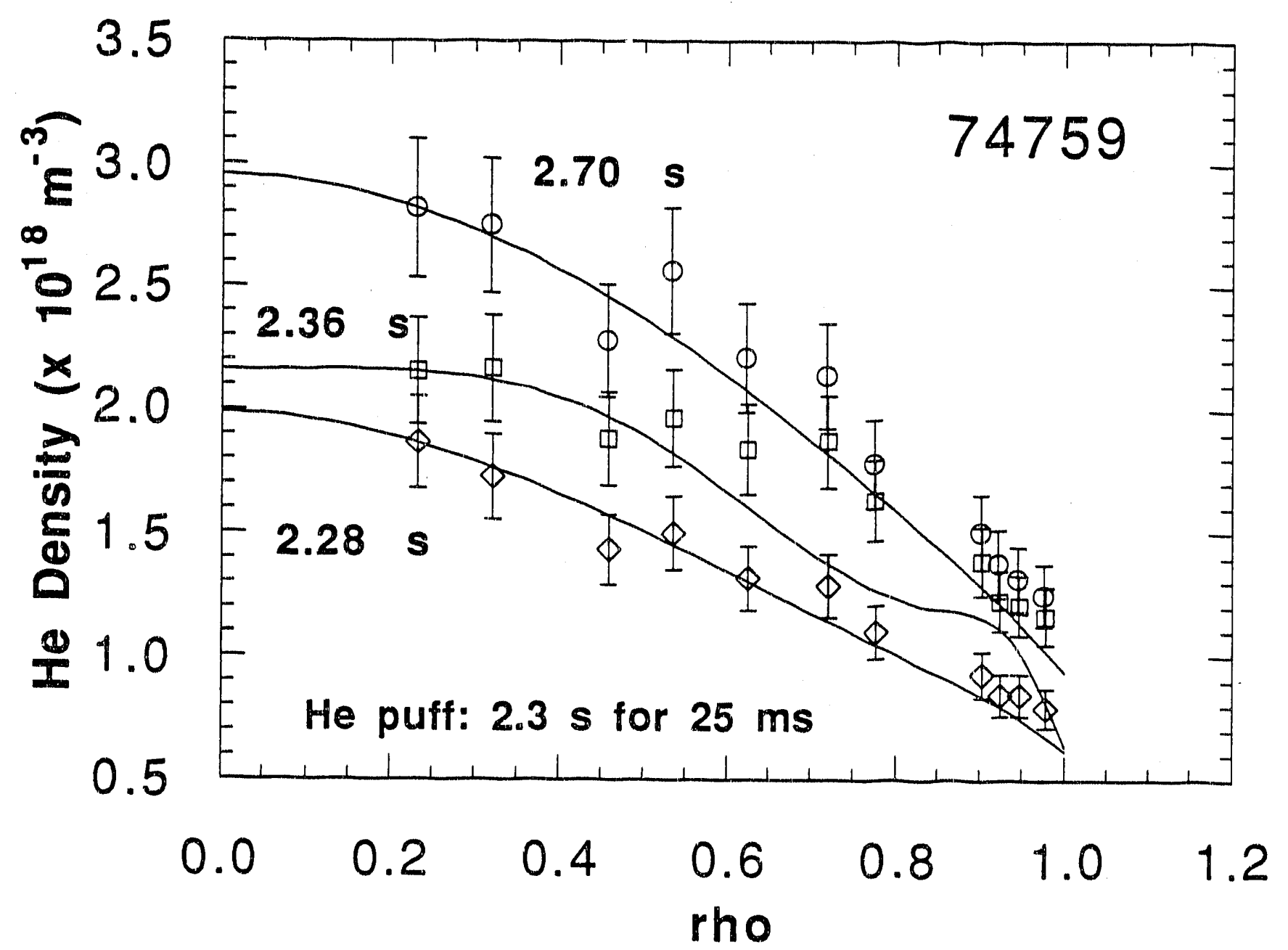

Fig. 8. He density profiles as measured by CER on DIII-D versus the normalized radius $\rho$ at three times during the discharge: $t=2.28 \mathrm{~s}$ just before the gas puff; $t=2.36 \mathrm{~s}$ just after the gas puff; and $t=2.70 \mathrm{~s}$, well after the gas puff. A $25 \mathrm{~ms} \mathrm{He}$ gas puff was injected at $t=2.3 \mathrm{~s}$. Points: are He density profiles measured by CER; solid lines are spline fits to the Thomson scattering measurements of the electron density. The electron density profiles have been normalized to the He density data at $\rho=0.23$ to compare the shapes of the profiles. 


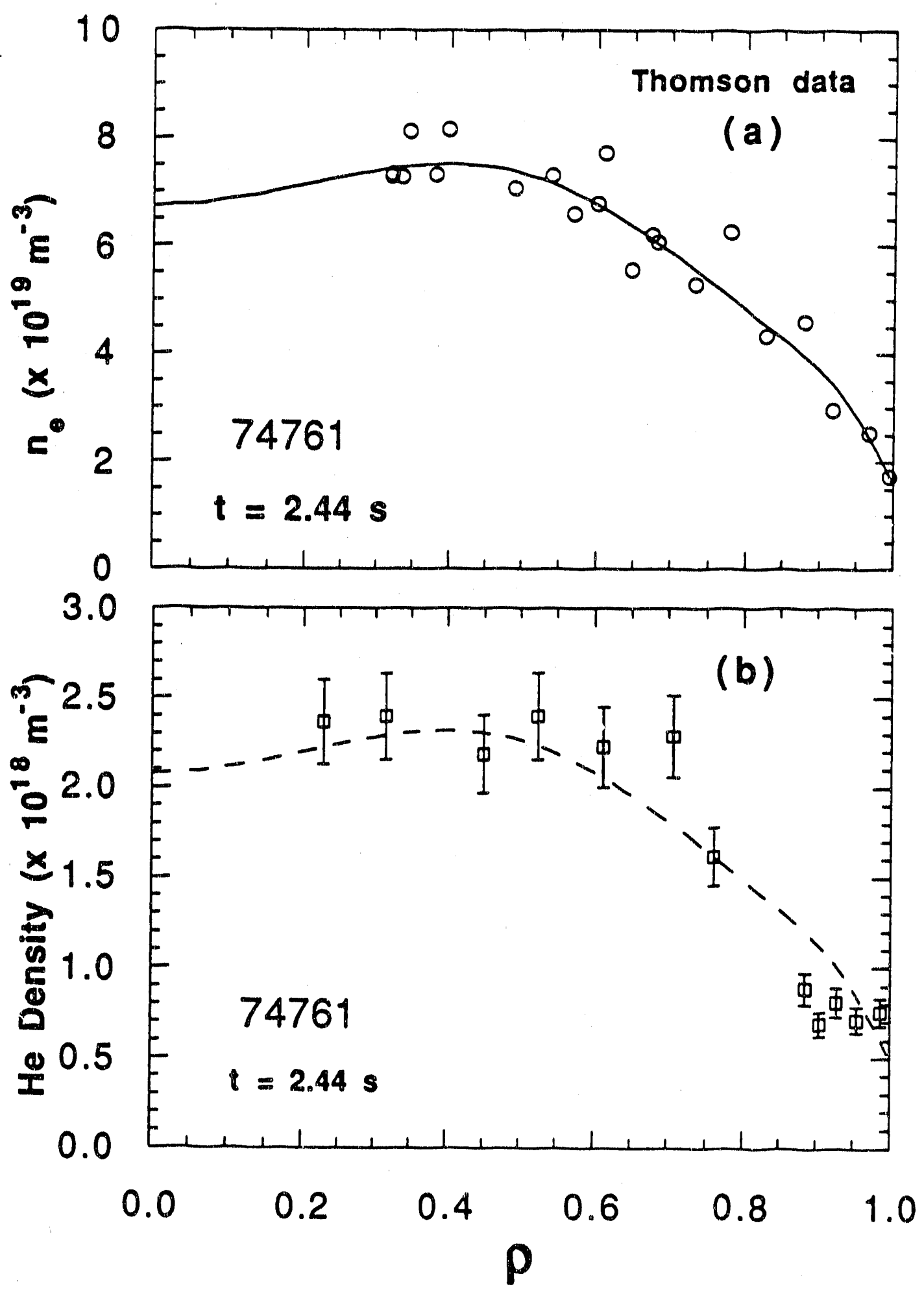

Fig. 9. (a) Electron density and (b) He density profiles versus $\rho$ as measured by Thomson scattering and CER spectroscopy for an L-mode plasma with $\bar{n}_{\mathrm{e}} \approx 6.5 \times 10^{19} \mathrm{~m}^{-3}$. In (a) the solid line is a spline fit to the Thomson scattering data; in (b) the dashed line is a $\mathrm{He}$ transport simulation with $R_{H e}=1.0, D_{A}=1.0 \mathrm{~m}^{2} / \mathrm{s}$, and $C_{V}=0.95$. 
those found for TEXTOR in the work discussed in Section 2 and Ref. [3] for L-mode. In addition, these results agree quite well with those of Ref. [6] from JT-60, where He neutral beam fueling has been used in $\mathrm{L}$-mode discharges, resulting in $D_{A} \approx 1.0 \mathrm{~m}^{2} / \mathrm{s}$ and $C_{\mathrm{v}} \approx 1.0$.

\subsection{Experiments in $\mathbf{H}-$ Moae}

To investigate the influence of $\mathrm{H}$-mode on $\mathrm{He}$ density profiles, the magnetic configuration and plasma current used in the experiments discussed in Sec. 3.1 are used. To induce H-mode, 10.4 MW of neutral beam power is injected for $200 \mathrm{~ms}$. To maintain an ELM-free H-mode, the beam power is then reduced to $4.4 \mathrm{MW}$. In shot 74773, an ELM-freeH-mode of about $0.5 \mathrm{~s}$.is

achieved. The resulting line-averaged electron density and the $\mathrm{D}_{\alpha}$ and $\mathrm{He}$ signals (measured by an array of photodiodes viewing the divertor floor at the strike point of the divertor flux) are shown in Fig. 10. Just after the He puff at $2.0 \mathrm{~s}$ the line-averaged density increases and both the He and $D_{\alpha}$ photodiode signals increase dramatically. The $D_{\alpha}$ signal increase is most likely due to the dramatic increase in electron density, which results from the He gas puff in the divertor chamber. From $2.1 \mathrm{~s}$ to $2.5 \mathrm{~s}$ in Fig. 10, an ELM free $\mathrm{H}$-mode is maintained, before the appearance of six giant ELMs. During the ELM-free period, the electron density continues to rise until $2.5 \mathrm{~s}$ when the first giant ELM appears; a slight drop in the density occurs with each of the subsequent giant ELMs.

The He density for shot 74773 is displayed in Fig. 11 for four spatial chords versus time (two chords near the plasma center, $\rho=0.32$ and 0.63 , and two edge chords, $\rho=0.90$ and 0.97). Just after the gas puff at $t=2.0 \mathrm{~s}$ the He appears at the plasma edge but requires about $200 \mathrm{~ms}$ to reach the plasma core. During the ELM-free phase of the discharge $(2.1-2.5 \mathrm{~s})$, the He density remains almost constant indicating a He recycling coefficient of unity. With the appearance of the first ELM at $2.52 \mathrm{~s}$, the He density at the edge drops significantly. It drops again with the occurrence of each successive ELM, but the central chords $(\rho=0.32$ and 0.63 ) remain almost unaffected. This indicates that the ELMs are expeling He from the plasma edge, 


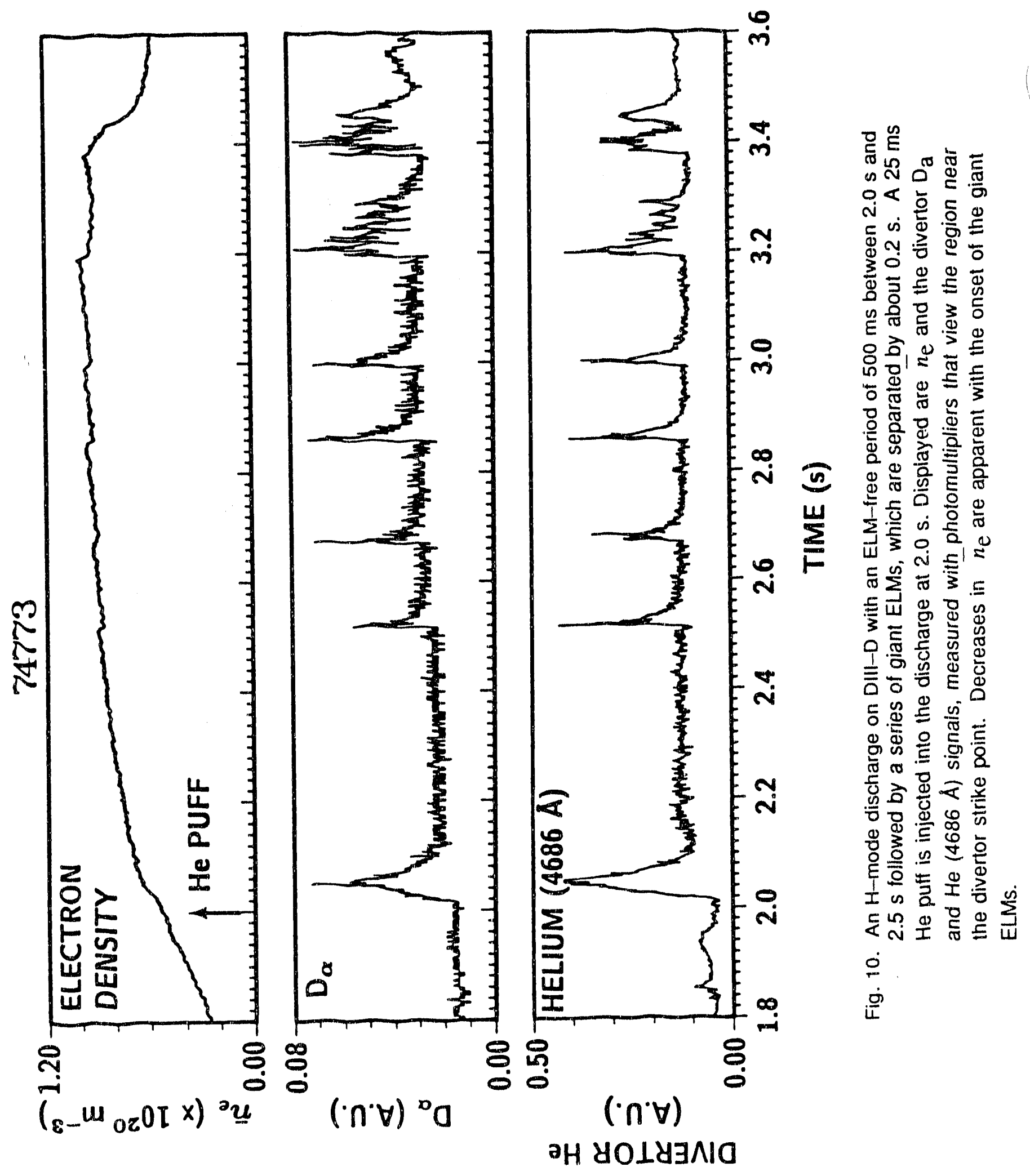



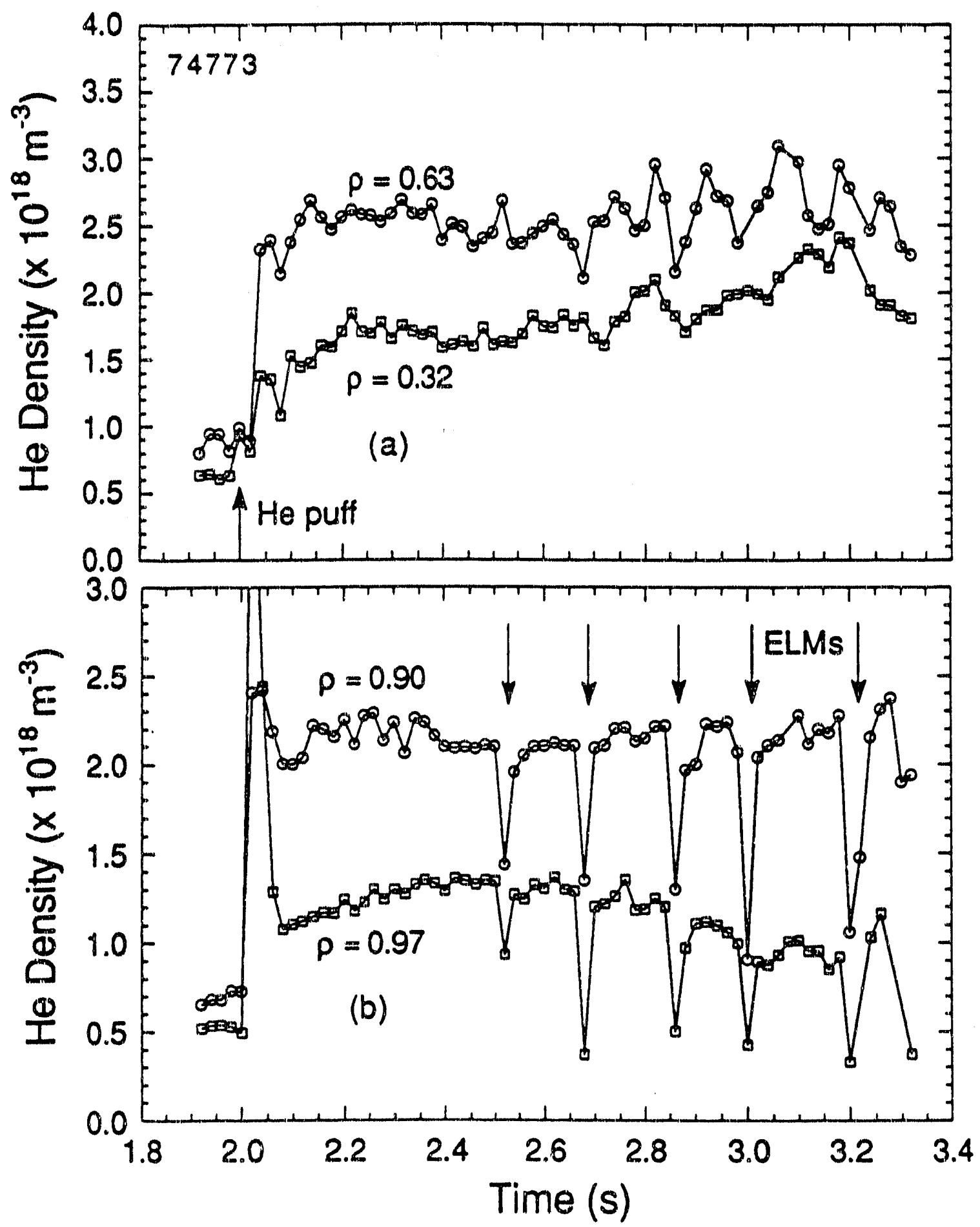

Fig. 11. Helium density evolution versus time for the $\mathrm{H}$-mode discharge shown in Fig. 10 at (a) two of the innermost plasma radii $(\rho=0.32$ and 0.63$)$ and (b) two outer plasma radii near the separatrix $(\rho=0.90$ and 0.97$)$. 
while the plasma center is not affected. In Fig. 12 the He density profile for shot 74773 is plotted versus $\rho$ for the ELM-free period $(t=2.36 \mathrm{~s})$ and compared to that of the electron density measured via Thornson scattering. During this ELM-free period both profiles have similar flat central profiles and steep edge gradients. The shape of the electron density : irofiles and the $\mathrm{He}$ density profiles are essentially the same. During this ELM-free period the energy confinement time $\tau_{\mathrm{E}}$ is found to be about $200 \mathrm{~ms}$, as measured by the diamagnetic loops.

To investigate the influence of ELMs on the He density profile, the electron density profile and the He density profile are displayed in Fig. 13 for the period of time just before $(t=2.94 \mathrm{~s})$ and during the giant ELM at $3.0 \mathrm{~s}$. The electron density rrofile (measured by Thomson scattering) in Fig. 13 indicates that density is lost from the edge plasma $(\rho>0.5)$ during the giant ELM. Similarly, the He density profile indicates that $\mathrm{He}$ is lost from the edge plasma for radii of $\rho>0.5$, while the profile is not affected for $\rho<0.5$. The He photodiode signals of Fig. 10 show that when the $\mathrm{He}$ is purged from the core plasma edge, the $\mathrm{He}^{+}$line emission from the divertor increases abruptly, suggesting a sharp increase in the divertor He content. If pumping were provided in the baffle region of DIII-D, this He could be removed. This is a clear de.monstration that ELMs purge He from the edge of the core plasma.

Finally, to an investigation of He density profiles during high-frequency giant ELMs, Fig. 14 displays the discharge 73922 . In this discharge, 9.7 MW neutral beams are injected from $2.3 \mathrm{~s}$ to $4.0 \mathrm{~s}$ with the $25 \mathrm{~ms}$ He gas puff occurring at $2.8 \mathrm{~s}$. Figures 14(a) and 14(b) show the line-averaged electron density and divertor $D_{\alpha}$ signal, respectively. The increased neutral beam power increases the frequency of the giant ELMs from that observed in discharge 74773 , as shown by the divertor $D_{\alpha}$ signal of Fig. 14(b). The He density profile, plotted versus $\rho$ in Fig. 15, drops quickly as $\rho$ is increased, and its general shape indicates that the ELMs are continuously expeling He from the edge of the core plasma. The shape of the electron density radial profile also agrees well with that found for the He density radial profile. The shapes of the radial profiles for this high-frequency ELMing discharge lie between the profiles observed for ELM-free discharges and those observed in L-mode or singular giant ELM events. If $\mathrm{He}$ 


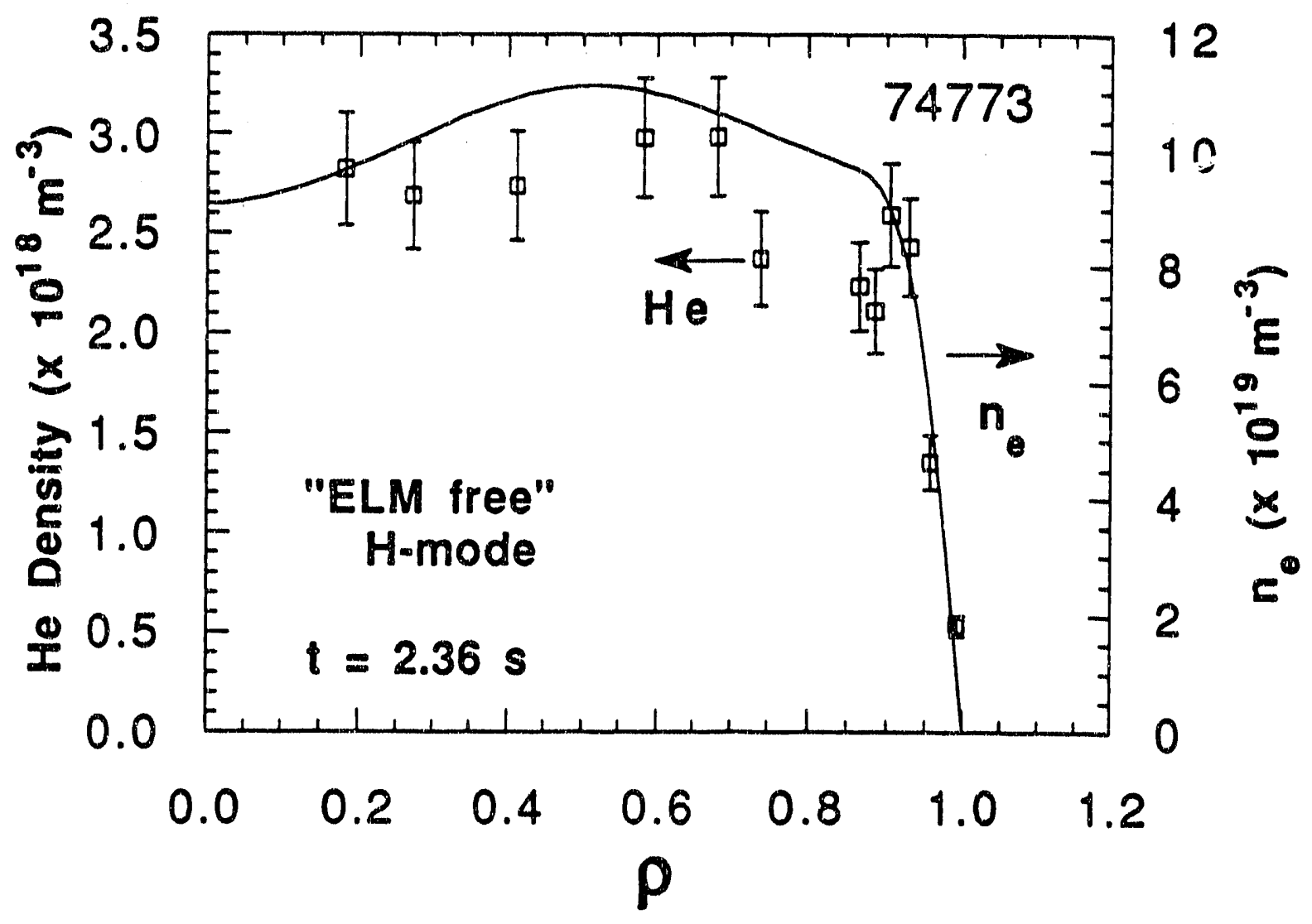

Fig. 12. Typical electron and He density profile for the ELM-free period of discharge 74773 at $t=2.36 \mathrm{~s}$. Points are Thomson scattering measurements of the electron density, ano' the solid line is a spline fit through the electron density data. The points with error bars are the He density data as measured by CER. 

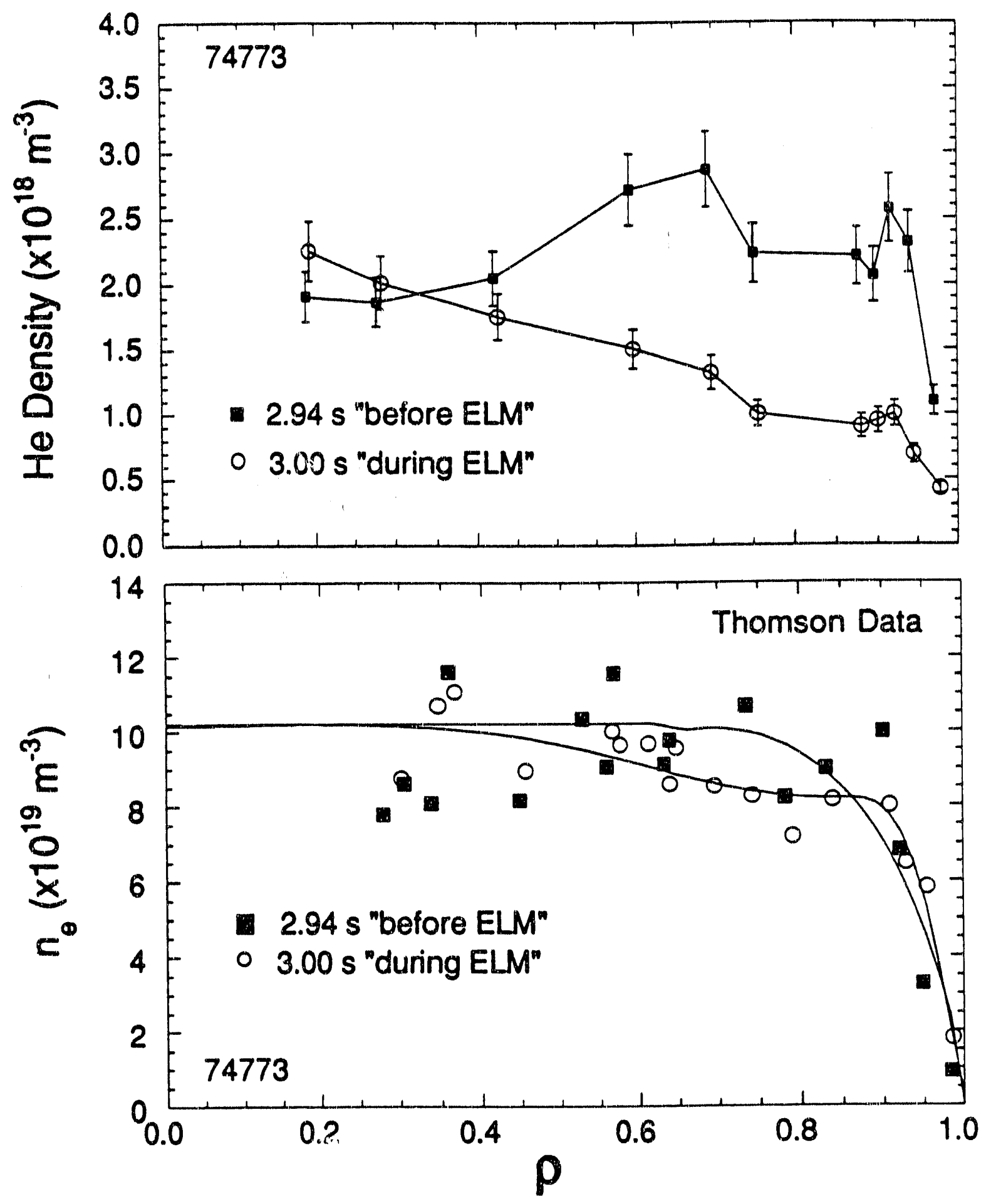

Fig. 13. (a) He density profile, as measured by CER, versus $\rho$ just before and during the giant ELM occurring at $3.0 \mathrm{~s}$ in discharge 74773 (shown in Fig. 10). (b) Electron density profile, as measured by Thomson scattering, versus $r$ just before and during this giant ELM. 


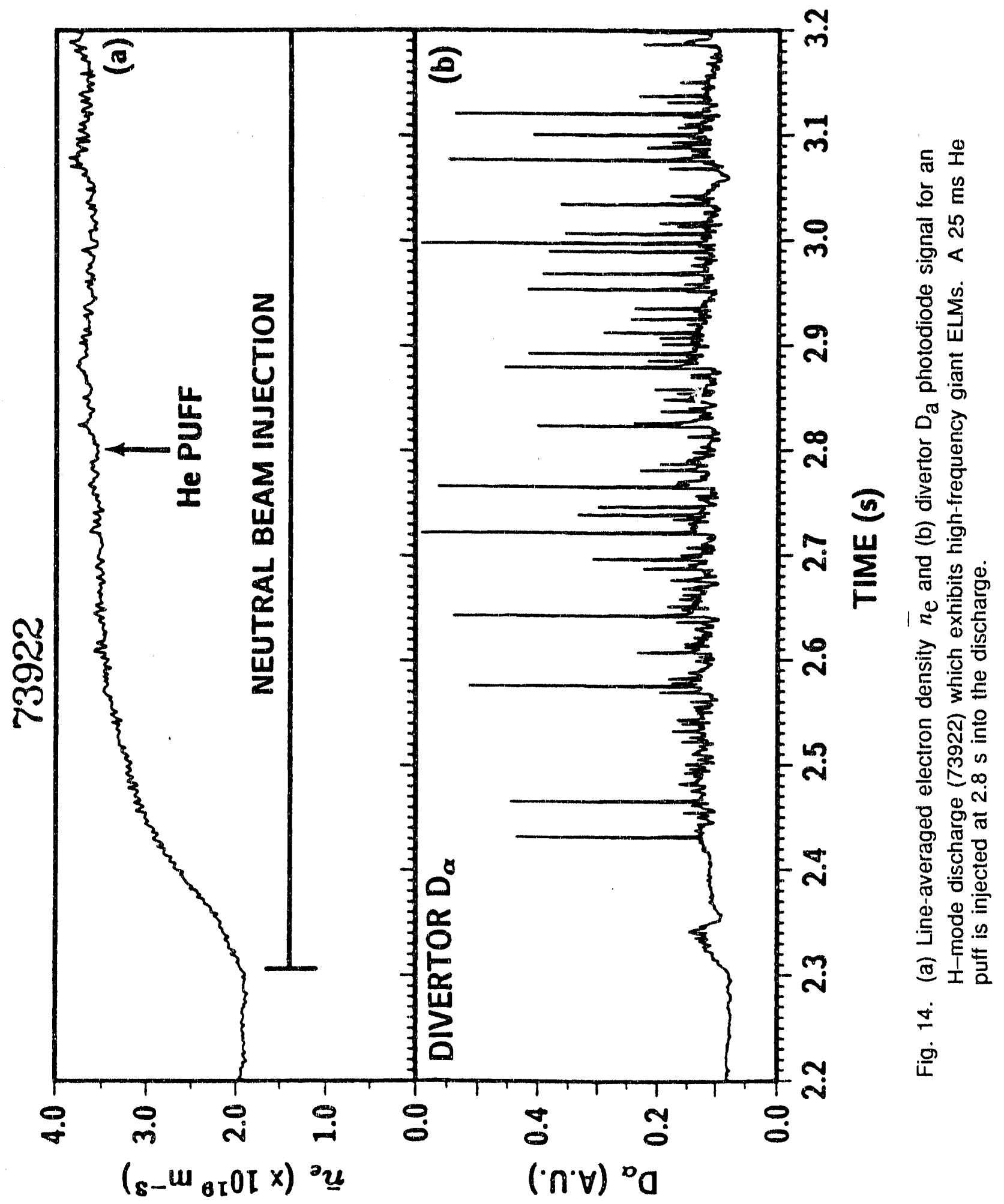




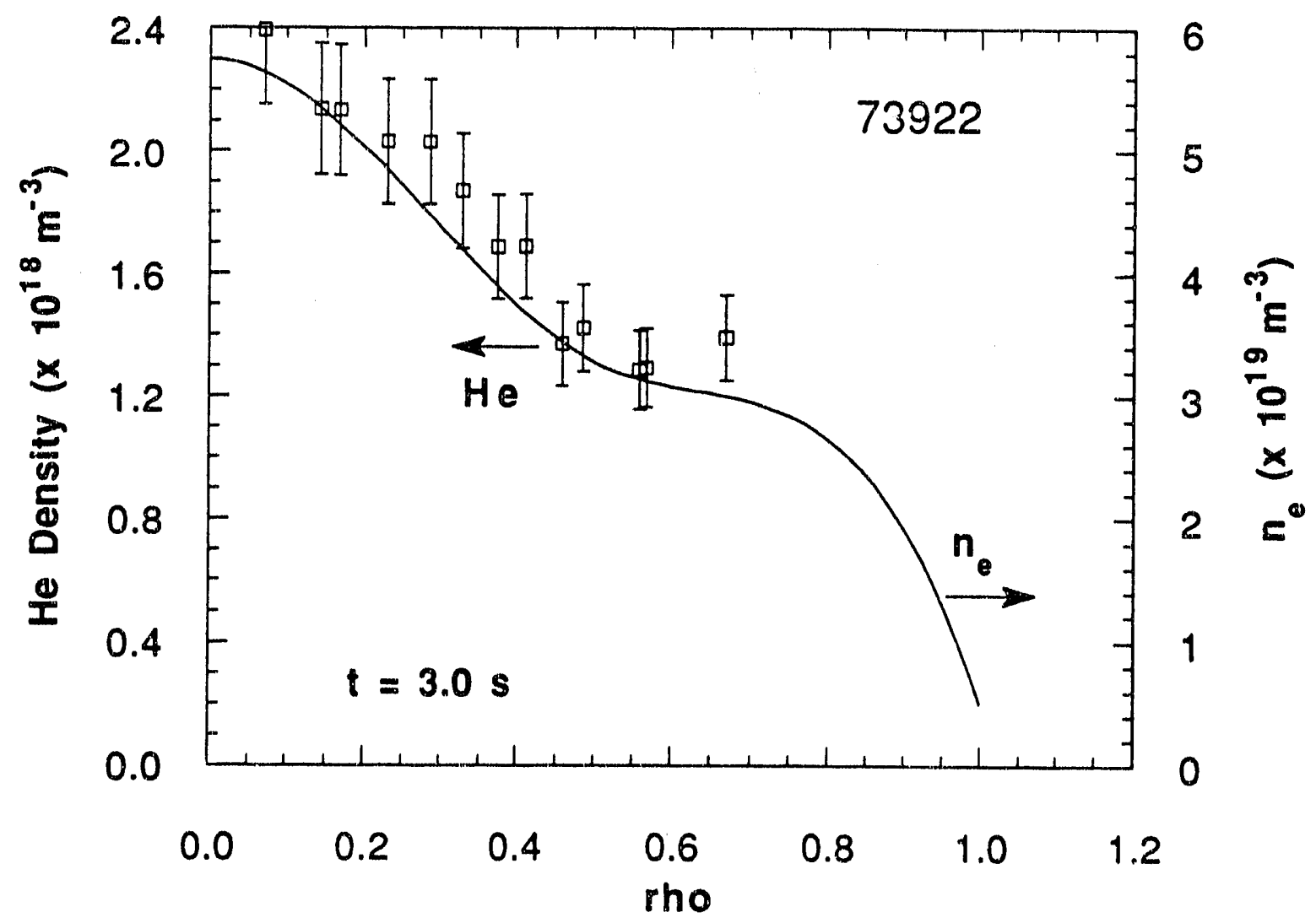

Fig. 15. The He density (points) as measured by CER and a spline fit to the electron density measured by Thomson scattering (solid line) versus $\rho$ for shot 73922 at $t=3.0 \mathrm{~s}$. 
pumping were available in the divertor chamber of DIII-D, the He lost from the plasma during these ELMs could possibly be removed. In general, it seems that, with appropriate control of the ELMs in a divertor tokamak, He removal can probably be achieved. Finally, Table I summarizes our results for the transport analysis of the discharges discussed here for both $\mathrm{L}-$ mode and $\mathrm{H}$-mode conditions with the $D_{A}$ and $C_{\mathrm{V}}$ values deduced from fitting the measured He profiles along with those found on a number of other tokamaks.

TABLE 1

ANOMALOUS DIFFUSIVITIES $D_{A}$ AND THE PINCH COEFFICIENT $c_{V}$ FROM IMPURITY TRANSPORT MODELING OF He ${ }^{2+}$ DENSITY DATA ON VARIOUS MACHINES

\begin{tabular}{|c|c|c|c|c|c|}
\hline Machine & Mode & $\begin{array}{l}\text { Shot Number } \\
\text { or Reference }\end{array}$ & $\begin{array}{l}\text { Helium } \\
\text { Pumping }\end{array}$ & $\begin{array}{c}D_{A} \\
\left(\mathrm{~m}^{2} / \mathrm{s}\right)\end{array}$ & $C_{V}$ \\
\hline TFTR & $\mathrm{L}$ & Ref. [5] & None & 10 & (a) \\
\hline JT-60 & L & Ref. [6] & None & 1.0 & $1.0-1.5$ \\
\hline PDX & Ohmic & Ref. [11] & None & 2.1 & 0.80 \\
\hline TEXTOR & $\mathrm{L}$ & Refs. $[2,3]$ & None & 1.0 & 1.50 \\
\hline TEXTOR & $\mathrm{L}$ & Refs. $[2,3]$ & Yes & 1.0 & 0.65 \\
\hline TEXTOR & L & 47425 & Yes & 1.0 & 0.80 \\
\hline TEXTOR & H (ELM-free) & 47426 & Yes & 1.0 & 1.15 \\
\hline DIII-D & L & 74759 & None & 1.0 & 0.95 \\
\hline DIII-D & $\mathrm{L}$ & 74761 & None & 1.0 & 0.95 \\
\hline
\end{tabular}

(a) The pinch velocity is 20 to $30 \mathrm{~m} / \mathrm{s}$ near the plasma edge. 


\section{SUMMARY AND CONCLUSIONS}

The He transport experiments on TEXTOR, in conjunction with the ALT-II pumping system, have provided a first estimate of fundamental He transport processes under conditions where both recycling and the type of confinement ( $\mathrm{L}$-mode versus $\mathrm{H}$-mode) are controlled and varied. When He is puffed into an L-mode type discharge, it quickly appears in the plasma core and is radially transporterd to the plasma boundary, where it is readily removed within about $1 \mathrm{~s}$ by the ALT-II pump limiter. When He is injected into enhanced confinement plasmas, it is not readily transported to the pumping duct if ELMs are not present. With the appearance of large ELM-like fluctuations, the He pressure in the pumping duct increases. Transport modeling has shown that the inward pinch coefficient, $C_{\mathrm{V}}$ (which characterizes the peaking of the He density profile relative to the $n_{\mathrm{e}}$ profile), increases significantly under enhanced confinement conditions, when the diffusivity is held fixed. For TEXTOR with the ALT-II pumped belt limiter, the data indicates that $\tau^{*} \mathrm{He} / \tau_{E} \approx 7^{\Upsilon}$ for an ELM-free enhanced confinement regime, which is induced by the polarization electrode. These measurements suggest that He removal may be more difficult in the enhanced confinement (or H-mode like) plasmas of future burning-plasma devices, such as ITER, than was found initially in Refs. [2-6].for L-mode-type plasmas. However, neither the control of the particle confinement via ELMs nor the control of sawtooth frequency was extensively tested in these experiments.

In the DIII-D experiments, a first look at the effects of ELMs on $\mathrm{H}$-mode He radial profiles has been presented. Detailed 11-point He density radial profiles were measured on DIII-D. Generally, the He density profile was found to have the same shape as the electron density profile. During ELM-free $\mathrm{H}$-mode operation, the He and electron density profiles are both flat in the plasma center and steep near the separatrix. During a giant ELM event, the He is purged from the plasma edge for $\rho>0.5$; it is observed in the divertor chamber as evidenced by an increase in a 
He photodiode monitor positioned in the divertor chamber. For giant ELMing events the He density profile is observed to approach the radial profile shape usually observed in the L-mode. For a discharge with high-frequency giant ELMs, the density profile is found to lie between that observed in an ELM-free H-mode discharge and that in an L-mode discharge. Again, the DIII-D results indicate that $\mathrm{He}$ is lost from the plasma edge during ELMing events and appears in the divertor chamber. These DIII-D experiments clearly indicate that ELMs modify the He radial profiles; this effect can be utilized to ultimately improve He pumping in a divertor tokamak. As part of the Advanced Divertor Project (ADP) on DII-D, a cryopump will be installed in late 1992. In principle, the cryopump could be conditioned with an Argon frost layer to provide He pump-ing. This will permit measurements of both $\tau^{*} \mathrm{He}$ and $\tau_{\mathrm{He}}$, similar to those done previously during the TEXTOR He experiments for which active He pumping was available.

It appears that additional work will be needed to understand He transport for the variety of H-mode conditions and the many types of ELMing conditions that can occur. He ash removal during high confinement $\mathrm{H}$-mode discharges, like those proposed for ITER, will probably require flushing of He from the core plasma by ELMs, as observed on DIII-D. Future experiments on DIII-D should help determine pumping efficiencies required in a divertor configuration to meet the requirement that $\tau^{*} \mathrm{He} / \tau_{E}<7-15$. 


\section{REFERENCES}

[1] D. Reiter, et al., Nucl. Fusion 30, (1990) 2141.

[2] D.L. Hillis, et al., Phys. Rev. Lett. 65, (1990) 2382.

[3] D.L. Hillis, et al., in Proceedings of the Thirteenth International Conference on Plasma Physics and Controlled Nuclear Fusion Research, Washington, D.C., 1990 (International Atomic Energy Agency, Vienna, 1991), CN-53/G-2-8, p. 597.

[4] K.H. Finken, et al., J. Nucl. Mater. 176 \& 177, (1990) 816.

[5] E. Synakowski, et al., Phys. Rev. Lett. 65, (1990) 2255.

[6] H. Nakamura, et al., Phys. Rev. Lett. 67, (1991) 2658.

[7] ITER Physics, ITER Documentation Series No. 21 (International Atomic Energy Agency, Vienna, 1991).

[8] R.R. Weynants, et al., in Proceedings of the Seventeenth European Conference on Controlled Fusion and Plasma Heating, Amsterdam, 1990 (European Physical Society, PetitLancy, Switzerland, 1990), Vol. 15C, Part I, p. 287.

[9] R.R. Weynants, et al., in Proceedings of the Thirteenth International Conference on Plasma Physics and Controlled Nuclear Fusion Research, Washington, D.C., 1990 (International Atomic Energy Agency, Vienna, 1991), CN-53/A-6-6.

[10] R. van Nieuwenhove, et al., in Proceedings of the Eighteenth European Conference on Controlled Fusion and Plasma Heating, Amsterdam 1990, (European Physical Society Abstract, Petit-Lancy, Switzerland, 1990), Vol.15C, Part I, p. 405.

[11] R.J. Fonck, et al., Phys. Rev. Lett. 52, (1984) 530.

[12] R. C. Isler, et al., Phys. Rev. A24, (1981) 2701.

[13] R. P. Seraydarian, et al., Rev. Sci Instrum. 57, (1986) 155.

[14] A. Boileau, et al., Plasma Phys. Controlled Fusion 31, (1989) 779. 
[15] D.M. Goebel, et al., J. Nucl. Mater. 162-164, (1989) 115.

[16] A. Hardtke, et al., J. Nucl. Mater. 162-164, (1989) 661.

[17] K.H.Finken, et al., Rev. Sci .Instrum. 63, (1992) 1.

[18] D.L. Hillis, et al., submitted to Nucl. Fusion Letters 1992.

[19] R.A. Hulse , Nucl. Technol./Fusion 3, (1983) 259.

[20] M.R. Wade, et al., submited to Rev. Sci. Instrum. (1992). 


\section{ACKNOWLEDGMENTS}

We are indebted to the TEXTOR and DIII-D diagnostic group for supplying general diagnostic information. We also gratefully acknowledge the contributions of the TEXTOR and DIII-D operations groups. One of us (DLH) would like to thank M. von Hellermann of the JET Joint Undertaking for his many helpful discussions and insight into the application of CER spectroscopy to the He density measurements.

Research sponsored in part by the Office of Fusion Energy, U.S. Department of Energy, under Contract DE-AC05-84OR21400 with Martin Marietta Energy Systems, Inc., and by the U.S. Department of Energy under Contract DE-AC03-89ER51114. 

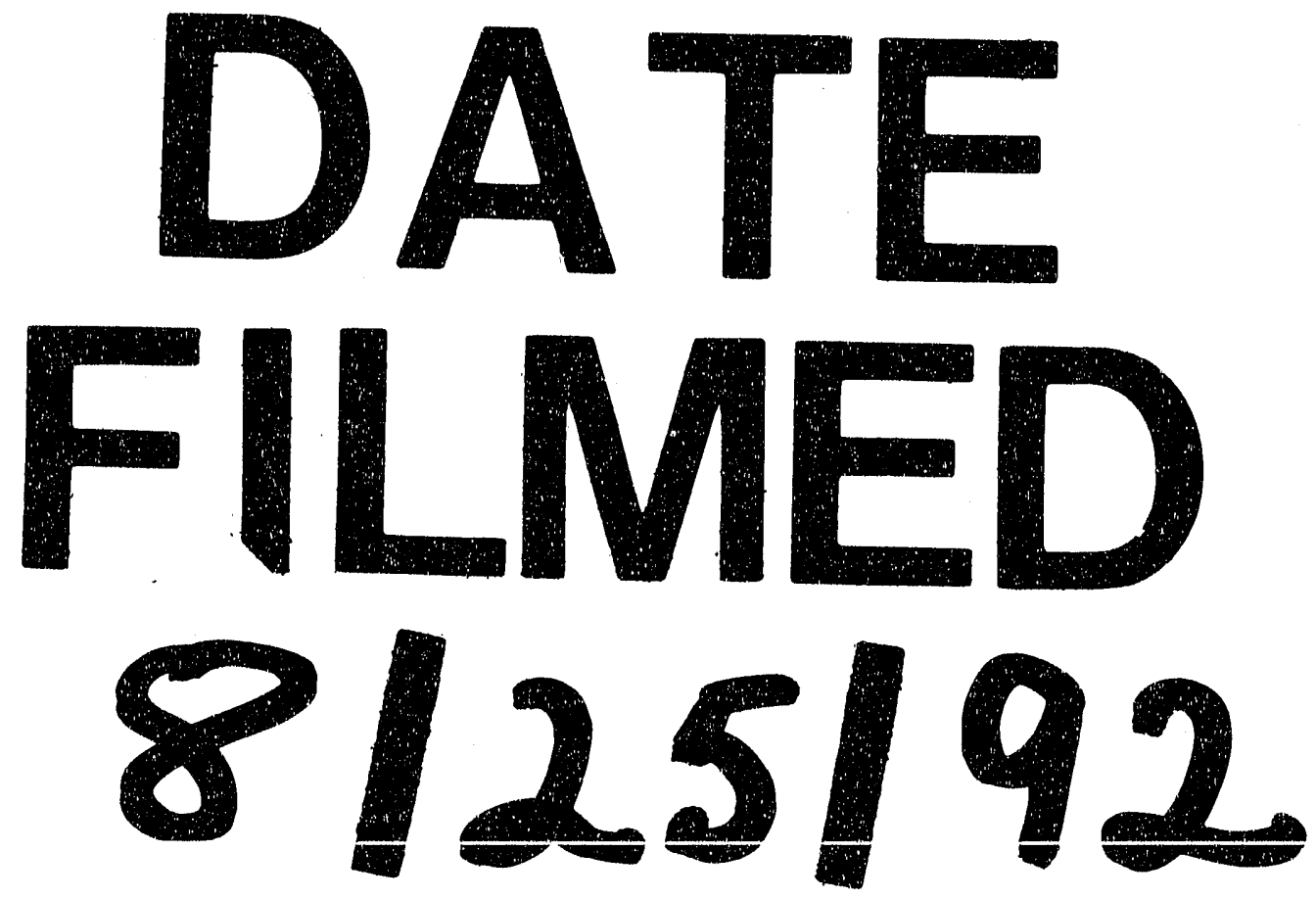
